\title{
Empleo y servicios sociales en la construcción de obras públicas:
}

\section{la transición política de Venezuela en $1936^{*}$}

\author{
Juan José Martín Frechilla \\ Universidad Central de VenezueIA
}

En 1936, durante la transición posterior al gobierno de Juan Vicente Gómez (1908-1935), el Ministerio de Obras Públicas se erigió en eje de la administración pública al emplear masivamente mano de obra desocupada en obras no siempre necesarias. Esta emergencia política y económica requirió de una reestructuración del ministerio que estuvo acompañada de programas de salud y educación para sus

funcionarios e inauguró un dispositivo cuya utilidad trascendió la coyuntura que analizaremos aquí.

INTRODUCCIÓN

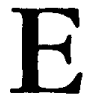

n Venezuela el crecimiento urbano no fue impulsado ni estuvo antecedido por un proceso de industrialización capitalista similar al que en Europa, con la revolución industrial, convirtió a la ciudad moderna, desde el último tercio del siglo XVIII, tanto en el objeto de un nuevo

* Se exponen aquí resultados de dos investigaciones en curso: "Orígenes del urbanismo moderno en Venezuela: 1830-1958. Influencias y traducciones", CONICIT, 95000440, y "Vivienda y saneamiento en la historia urbana de Caracas: 1830-1958", CDCH-UCV, 02.30.3455.95. negocio -el inmobiliario- como en el escenario de las luchas sociales de los obreros por mejorar unas condiciones de trabajo y de vida insostenibles, a la vez que la volvió sujeto de estudio, acción y control. Así, para explicar esta urbanización se debe recurrir a la clave petrolera, cuya "fortuita" irrupción hizo posible la intervención del Estado, su expansión y modernización institucional. El fomento, la inversión en obras públicas y el empleo burocrático fueron un percutor incontenible y reiterado de raigambre urbana que exponenció el proceso, aunque este salto de escala no debe oscurecer la red de 


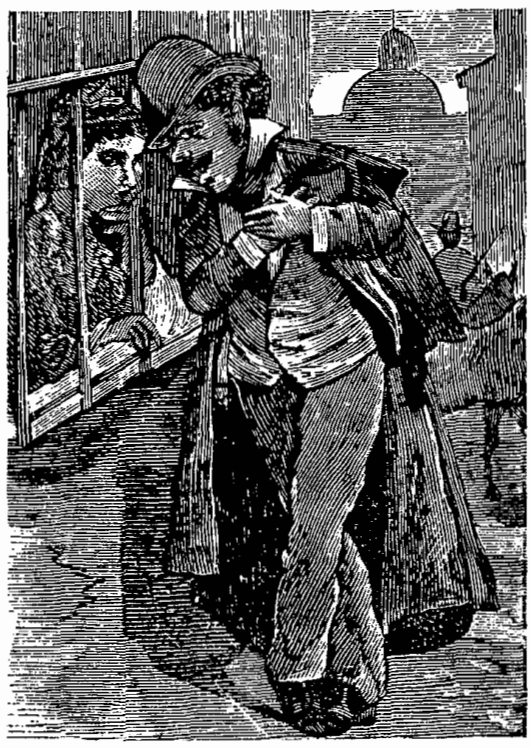

carreteras construida entre 1908 y 1925 , durante el gobierno de Juan Vicente Gómez, antes de que el petróleo ocupase el puesto que todavía mantiene en las exportaciones. ${ }^{1}$

Es posible destacar también una disimilitud parecida entre lo ocurrido en el país y la forma como, en Gran Bretaña, Francia y Alemania, las tensiones de los distintos procesos nacionales engarzados a la revolución industrial dieron por resultado la implantación en esos países de estructuras legales $\mathrm{e}$ institucionales sobre el trabajo y la asis-

\footnotetext{
'Véase Martín Frechilla, Planes, 1994, pp. 262-267.
}

tencia y la seguridad sociales. ${ }^{2}$ En Venezuela, los transplantes y las traducciones asumidas sobre estos asuntos, al menos en sus orígenes, fueron propuestos por el Estado, pero sin que la mayor parte de las veces una presión social significativa empujase su adopción. De modo que, tanto la urbanización como el dispositivo de legislación laboral del país, fueron el resultado de otras fuerzas, de otros atajos, si bien la lógica que los arropa pertenece a un manto similar, occidental y capitalista. Pero, al margen de los desfases temporales con esas realidades, la diferencia entre las leyes sociales venezolanas y el aparato institucional que las encuadra no estriba en que se haya tomado ventaja o quemado etapas en su adopción, como lo hizo Francia durante el siglo XIX, pero sobre todo Alemania, frente a la pionera Gran Bretaña. En Venezuela, estos temas cuajaron al final de la década de 1930, cuando la producción de petróleo había sancionado la riqueza del país, pero también cuando el debate internacional sobre los papeles del Estado -providencial, benefactor, productor, empleador- estaba redimido, en parte, de su matriz socialista, y había adoptado la keynesiana forzado por las circunstancias. ${ }^{3}$ Sobre esta trama, a partir de 1936 se ensayará y aprobará en Venezuela un abultado grupo de iniciativas públicas -de las cuales aquí nos vamos a ocupar

\footnotetext{
${ }^{2}$ Caso aparte es el de Estados Unidos, allí la previsión social moderna siguió otros cauces no ajenos a la guerra de Secesión. Véase Skocpol, Origenes, pp. 23-105.

${ }^{3}$ En Venezuela, el Estado es propictario del subsuelo nacional.
} 
de las relacionadas directa o indirectamente con la construcción de obras públicas-, encadenadas con tal rapidez que delatan una elaboración anticipada cuyas trazas externas es necesario recorrer a fin de situar la coyuntura particular de 1936.

La temprana constatación de que la pobreza, la miseria urbana generada por la revolución industrial, podía constituir un peligro social y político, hizo que se incorporase al ideario liberal la "cuestión social". Sin embargo, el camino europeo para que se asumieran como un asunto de Estado las consecuencias sociales y económicas de la modernización capitalista duró aproximadamente un siglo (digamos 18301930), tuvo recorridos nacionales diversos y estuvo sacudido por violentos enfrentamientos obrero-patronales. En Gran Bretaña, en donde desde el siglo XV la reforma religiosa y una ley de los pobres habían hecho de la filantropía -confesional o laica- un asunto de iniciativa privada, los males sociales y morales de las masas populares urbanas fueron enfrentados como una enfermedad que era necesario curar. Para ello existían en Londres en 1824, Biblia en mano, más de 300 instituciones privadas, entre misiones, sociedades filantrópicas, escuelas de caridad y ejércitos de salvación. ${ }^{4}$ En Francia, una filantropía menos confesional puso en funcionamiento, entre 1800 y 1848 , "los primeros dispensarios, las primeras escuelas de enseñanza mutual y profesional, las primeras cajas de ahorro, los primeros patronatos, las primeras

\footnotetext{
"Véase Barret-Ducrocq, "Mobilisation", 1994, pp. 17-28.
}

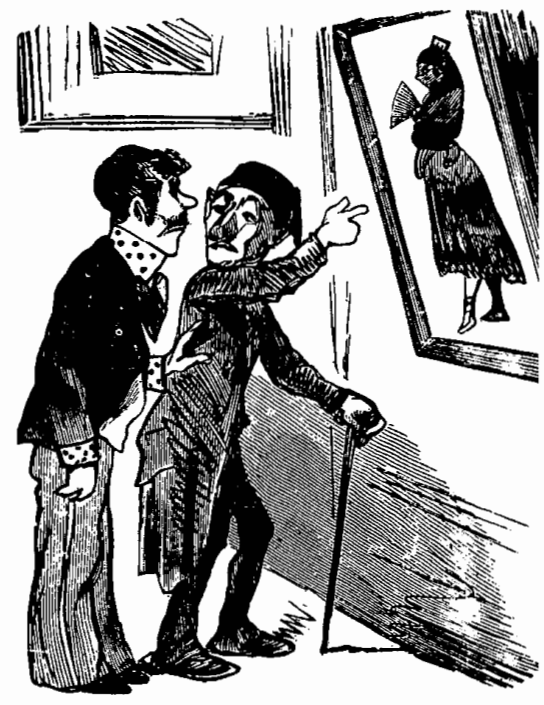

salas de asilo, las primeras colonias agrícolas, las primeras guarderías". 5 En Alemania, la tardía industrialización, además de las ventajas para el proceso de desarrollo económico, permitió una aproximación más analítica y menos moral de la "cuestión social" que se vio plasmada en la fundación, en 1844 , de una Asociación Central para el Bienestar de las Clases Trabajadoras cuyo acento fundamental estaba puesto en el ahorro y la educación como accio-

\footnotetext{
5Véase Dúprat, "Lumières ", 1994, p. 12 (traducido por nosotros).

${ }^{6}$ Pudo contribuir a ello la existencia de textos claves de autores alemanes sobre las experiencias francesas y británicas. La situación de la clase obrera en Inglaterra, de Engels, publicado en 1845 , es un buen ejemplo.
} 
nes filantrópicas liberales asentadas en la autoayuda. ${ }^{7}$

Pero el retraso en la industrialización alemana se convirtió en precocidad a la hora en que el Estado, luego de la unificación en 1870, adoptó las más avanzadas políticas sociales -seguro de enfermedad obligatorio, de accidentes, de invalidez y vejez con cotizaciones repartidas entre patronos y asalariadosy una organización institucional de la administración pública para la asistencia social. En Inglaterra, por su parte, desde el Edicto de Speenhamland en 1795 , se habían adoptado los subsidios a los obreros como complemento al salario conforme a un baremo indexado al precio del pan, de forma tal de garantizar un ingreso mínimo independiente de lo que ganasen. Además, el nivel del beneficio estaba determinado por el número de hijos, que quedaban así incluidos en los subsidios familiares. ${ }^{8}$ Sin embargo, la resistencia a que los poderes públicos asumieran como su responsabilidad los problemas de las capas más pobres de la población sólo comenzó a mostrar fisuras alrededor de la década de 1860. Prueba de ello fueron los programas de destrucción de tugurios y la reubicación de los desalojados, y las leyes contra el sweating system por medio de la adopción de límites a la duración de la jornada de trabajo. También son ejemplos de políticas selectivas la aprobación, en 1870, de la enseñanza pública obligatoria en manos del Estado y la

\footnotetext{
7 Véase Kott, "Solutions", 1994, pp. 177-185.

${ }^{8}$ Véase Tanghe, Droit, 1989, pp. 190-192.

"Véase Barret-Ducrocq, "Mobilisation", 1994, p. 19.
}

clasificación de los pobres de Charles Booth, con su plano de la pobreza de Londres (1886-1903) en el que establece grados y niveles, clasifica a los desempleados entre los que tienen derecho a los subsidios -obreros estables que han cotizado, de empleo regular y temporalmente sin trabajo- y los que no lo tienen, como paso previo a la adopción de los seguros de desempleo. ${ }^{10}$ En Francia, la revolución de 1848 avivó, en la Asamblea Constituyente, el debate sobre la intervención del Estado alrededor del derecho al trabajo. El Estado-providencia y la herencia de la revolución de 1789 estuvieron presentes en los discursos -Blanc, Lamartine, Proudhon...- hasta que las garantías del derecho al trabajo se abrie. ron camino en el texto constitucional, incluyéndose entre ellas:

la libertad de trabajo, la asociación voluntaria, la igualdad en las relaciones entre el patrón y el obrero, la enseñanza gratuita, la educación profesional, las instituciones de previsión y de crédito y la realización por parte del Estado de grandes obras de utilidad pública destinadas a emplear en caso de desempleo a los brazos desocupados. ${ }^{11}$

Con esta última vinculación entre las obras públicas y las políticas de empleo, cerramos las trazas externas necesarias para abordar al Ministerio de Obras Públicas (MOP) en la Venezuela de 1936. No es el caso aquí buscar ni detallar, en los textos constitucionales

\footnotetext{
${ }^{10}$ Véase Topalov, "Invention", 1987, pp. 5392, y "Enquète", 1991, pp. 5-34.

${ }^{11}$ Véase art. 132 de la Constitución de 1848 citado por Tanghe, Droit, 1989, p. 182.
} 
y las leyes venezolanas, las referencias de lo importado. Sin embargo, no parece aventurado afirmar que, entre la obligación de trabajar establecida por una Diputación Provincial en la ciudad de Cumaná en 1836 so pena de ser reputado como vago y sujeto de arresto, y la primera Ley del Trabajo promulgada en 1928 a fin de dar cumplimiento con los acuerdos de la Oficina Internacional del Trabajo, ${ }^{12}$ pocas son las disposiciones legales e institucionales que es posible rescatar sobre el régimen laboral, la asistencia, la seguridad social y la protección de los trabajadores venezolanos. ${ }^{13} \mathrm{La}$ iniciativa privada, mayoritariamente de tipo confesional, había estado desde el siglo XIX encauzada a la atención caritativa de los pobres, mientras el sector público atendía precariamente la salud en hospitales y lazaretos por medio de las rentas municipales. ${ }^{14}$ La prevención de los accidentes de trabajo y la asistencia médica de los trabajadores quedó recogida por primera vez en el país en el ámbito restringido del Código de Minas aprobado en $1910 .{ }^{15}$ En el Pri-

\footnotetext{
${ }^{12}$ Ese año, César Zumeta (1860-1955), el decano de los representantes de Venezuela en la Sociedad de las Naciones, pasó a formar parte del consejo del organismo, por lo cual lució necesario adoptar una legislación que tuvo pocos efectos prácticos. Véase Vivas, Venezuela, 1981, pp. 256-261. Mientras no se indique lo contrario, utilizaremos las referencias biográficas del Diccionario de Historia de Venezuela, 1997, a fin de situar a los personajes.

${ }^{13}$ Véase Parra Aranguren, Antecedentes, 1965 , pp. 39-76 y pp. 171-177.

${ }^{14}$ Véase García Ponce, Pobres, 1995, pp. 203-319.

${ }^{15}$ Véase Parra Aranguren, Antecedentes, 1965, pp. 30-31.
}

mer Congreso de Municipalidades de 1911 fueron presentadas algunas iniciativas -que no prosperaron- a fin de adoptarlas como competencias locales y nacionales: la creación en Caracas de "un asilo para niños de ambos sexos en donde las obreras y otras madres pobres, que tengan que trabajar durante el día fuera de sus casas, dejen a sus hijos"; un reformatorio de "reclusión para las niñas abandonadas, en donde reciban instrucción elemental, principios de moral y buenas costumbres y enseñanza de trabajos domésticos", ${ }^{16}$ y un proyecto de ley sobre accidentes de trabajo, que los clasificaba y calificaba, incluía como obligación que el patrono se hiciese cargo de los gastos médicos y que cubriese la mitad del salario mientras durase la incapacidad; proponiendo, también, para los casos de muerte o incapacidad, la creación de una Caja de Ahorros para Accidentes de Trabajo, a la cual contribuirían tanto los patronos como los obreros, además de los Concejos Municipales. ${ }^{17}$ No es entonces extraño que la mayor parte de los especialistas sobre legislación laboral, seguridad y asistencia social, concentren sus análisis a partir de las iniciativas desplegadas en 1928 y confirmadas en 1936 , ubicando como antecedentes, no siempre valorados de igual forma, las trazas anteriores a estas fechas. ${ }^{18}$ Es posible afirmar

16 Véase Pensamiento, 1983, núm. 9, p. 218.

${ }^{17}$ Véase Pensamiento, 1983, núm. 9, pp. 289-291

${ }^{18}$ Véase Parra Aranguren, Antecedentes, 1965; Caldera, Derecho, 1939; Díez, Estudios, 1940; Parra, Accidentes, 1942; Zúñiga Cisneros, Ensayos, 1973; Mora Contreras, Seguridad. 
sin demasiados riesgos que el primer dispositivo moderno para el trabajo y la seguridad social se asentó en Venezuela en 1936.

PRIMERA PARTE: EL PlaN

DE EMERGENCIA

La muerte natural, el 17 de diciembre de 1935, del general Juan Vicente Gómez, luego de ejercer el poder en Venezuela desde 1908, dio origen a un inevitable debate sobre la forma y la dirección de la transición política. Debate entre quienes aspiraban a una continuidad, a una evolución sin traumas, y quienes buscaban superar, por medios más o menos radicales, la trama social enquistada en el poder durante tantos años, y en un país que ya había dejado de ser agroexportador para convertirse, al final de la década de los veinte, en el segundo productor mundial de petróleo y el primer exportador. El general Eleazar López Contreras (1883-1973), ministro de Guerra y Marina, asumió como encargado la presidencia de la república, fue confirmado en el cargo por el Congreso $\mathrm{Na}$ cional y elegido por éste, en abril de 1936 , para un periodo constitucional de siete años, 1936-1943, posteriormente reducido a cinco al promulgarse la nueva Constitución. De modo que, el 1 de enero de 1936, el general López Contreras tomó el juramento de ley a su primer gabinete. Era el inicio de un proceso de transición hacia una sociedad menos autoritaria, más abierta,

1978; Gutiérrez Alfaro, Documentos, 1966; Boggiano y Mújica, Seguridad, 1972. que al confirmar su vocación urbana iba a adoptar progresivamente, entre oscilaciones, prevenciones y restricciones, a trompicones y dando muestras episódicas de arbitrariedad, un régimen de partidos, con sindicatos y algunas libertades políticas. ${ }^{19}$

El gabinete ejecutivo incluía novedades suficientes como para presumir intenciones de cambio. La seguridad y la defensa del orden público seguía estando en manos de "Los Andinos", 20 que en el caso de los encargados del Ministerio de Relaciones Interiores y de la Gobernación del Distrito Federal -Diógenes Escalante (1879-1964) y

19 Véase Battaglini, Legitimación, 1993; Chiossone, Decenio, 1989; Moleiro, Dictadura, 1993; Polanco Alcántara, General, 1985; Hermoso, 1936, 1991.

${ }^{20}$ En 1830 , Venezuela se separó de la Gran Colombia e inició vida republicana independiente. Buena parte del siglo XIX estuvo marcada por la inestabilidad política y las dificultades de recuperación económica. El centro del país fue escenario militar fundamental de alzamientos y montoneras que terminaron, entre 1859 y 1863 , en una cruenta guerra civil, la llamada guerra federal. La relativa prosperidad de la región cafetalera de Los Andes - casi al margen de estos conflictos-, y su relegamiento por el poder central, culminó, luego de una campaña militar, con la instalación en Caracas de sus representantes cuando estaba por iniciarse el siglo xx. "Los Andinos" tardaron en abandonar el poder: Cipriano Castro, 1899-1908, Juan Vicente Gómez, 1908-1935, Eleazar López Contreras, 1935-1941, e Isaías Medina Angarita, 19411945. Los cuatro generales andinos fueron, uno tras otro, presidentes. Después del trienio 1945 1948 , de impronta socialdemócrata, con Rómulo Betancourt como presidente de una Junta Revolucionaria y Rómulo Gallegos como presidente constitucional, en 1948 se inició, hasta 1958, una década bajo la conducción -primero compartida y luego en solitario- de Marcos Pérez Jiménez, otro general andino. 
Felix Galavís (1877-1941)-, provenían además del colegio de El Sagrado Corazón de La Grita, en donde también había estudiado López Contreras. Sin embargo, la presencia de Escalante en el gabinete era una señal para marcar diferencias. ${ }^{21}$ Así como Galavís estuvo ligado primero al gobierno de Cipriano Castro y luego al de Juan Vicente Gómez, con responsabilidades militares y políticas importantes, los vínculos de Escalante durante ambos gobiernos fueron discretos y sin compromisos, salvo algunos cargos menores en la política interior durante el primer gomecismo (1908-1918). Así, el nuevo ministro de Relaciones Interiores había iniciado su carrera diplomática como cónsul de Venezuela en Liverpool en 1904; la interrumpió entre 1910 y 1915 , cuando estuvo en Venezuela como director de la Imprenta Nacional y de un periódico, para regresar a Europa en 1915, en donde permaneció hasta 1935 cuando, a la muerte de Gómez, volvió al país. Además de ministro plenipo-

21 Diógenes Escalante había sido maestro de escritura de López Contreras en 1893 en dicho colegio. Véase López Contreras, Proceso, 1955, p. 40. La Grita es una población situada en el estado Táchira, el más occidental de los estados andinos. El Colegio Sagrado Corazón de Jesús, hoy Liceo Jáuregui, fue fundado en 1884 por monseñor Jesús Manuel Jáuregui (1848-1905), sacerdote y educador. En 1886 el colegio, por el cual han desfilado gran cantidad de personajes influyentes de la vida pública venezolana. obtuvo del Congreso Nacional el permiso para otorgar el titulo de bachiller, y del Obispado la concesión para que "Ios alumnos con vocación sacerdotal vistieran sotana e hicieran en el colegio sus estudios teológicos". Monseñor Jáure. gui estudió en Europa, y en especial en Turín, el sistema pedagógico de los institutos sale. sianos que luego aplicaría en La Grita. tenciario en Gran Bretaña, estuvo, casi sin interrupción entre 1920 y 1935 , como uno de los representantes por Venezuela en la Sociedad de las Naciones. ${ }^{22}$ El largo extrañamiento de Escalante del país era, en aquellas circunstancias, invalorable para López Contreras, como quedó demostrado cuando el ministro del Interior sorteó con éxito las violentas manifestaciones antigomecistas de febrero de 1936, que terminaron con la designación de un nuevo gabinete el 21 de febrero. ${ }^{23}$ El gobernador Félix Galavís fue la principal cabeza de turco de este ajuste, que procuraba ofrecer garantías y convencer sobre el deslinde que el nuevo régimen quería marcar del antiguo.

Escalante superó las dos siguientes modificaciones del gabinete hasta que, en la del 29 de abril de 1936, dejó el ministerio por la secretaría general de la presidencia. ${ }^{24}$ Pocos meses después

22 Escalante fue representante junto a Manuel Diaz Rodríguez (1871-1927) y Santiago Key Ayala (1874-1959), en 1920; junto a Caracciolo Parra Pérez (1888-1964) y Santiago Key Ayala, en 1921, y junto a César Zumeta y Caracciolo Parra Pérez, de 1924 a 1928 y de 1930 a 1935. Véase Vivas, Venezuela, 1982; Villegas, Política, 1993. La historiografia venezolana designa a estos personeros del gobierno gomecista, junto con otros que irán apareciendo, como el "grupo de Ginebra", en referencia a la ciudad sede de la Sociedad de las Naciones; a la permanencia de los funcionarios en distintos cargos de la delegación, y a la irrupción de buena parte de ellos en la vida política de la transición (19351945), a la muerte de Juan Vicente Gómez.

${ }^{23}$ Véase Fuenmayor, Historia, 1976, pp. 268-269.

${ }^{24}$ El 2 de marzo de 1936, se incorporaron Isaías Medina Angarita (1897-1953), al Ministerio de Guerra y Marina; Alberto Adriani (1898-1936), al de Agricultura y Cría, y Carac- 


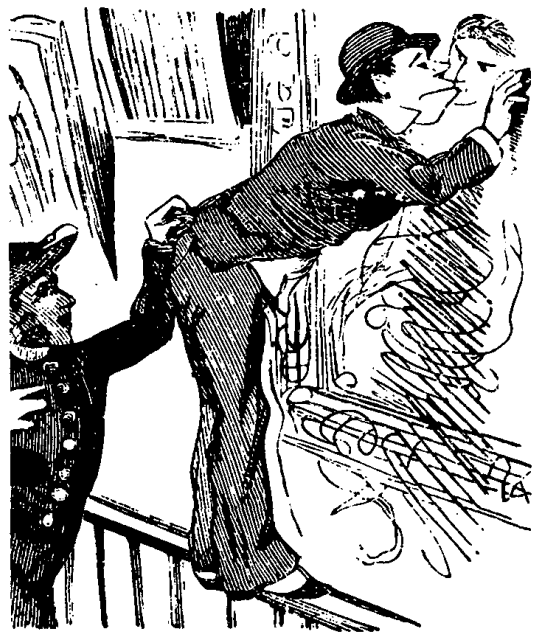

solicitó, nuevamente, su incorporación al servicio diplomático, y fue nombrado embajador de Venezuela en Estados Unidos, cargo que no abandonó sino hasta 1945 , al ser designado candidato a la presidencia de la república. ${ }^{25}$ Sin embargo, en su caso todo parece indicar que la clave del extrañamiento de 1936 fue una petición personal y no un requerimiento político. Así, durante esos primeros meses de la transición, fueron decisivos los aportes de

ciolo Parra Pérez, al de Instrucción Pública. El 26 de marzo, Rómulo Gallegos (1884-1969) sustituyó a Parra Pérez como ministro de Instrucción Pública. Véase Fuenmayor, Historia, 1976, pp. 269-270. Recordemos que Parra Pérez, Adriani y Medina Angarita eran andinos.

${ }^{25} \mathrm{Su}$ enajenación mental al poco tiempo de llegar al país constituye uno de esos episodios claves para quienes le preguntan a la historia "qué hubiese sucedido si...".
Escalante dentro de lo que se denomina el "grupo de Ginebra" y en la puesta en práctica del Programa de Febrero. ${ }^{26} \mathrm{El}$ ideario modernizador se basaba en una reforma legal e institucional capaz de apoyar las necesidades político-administrativas de los puntos del programa: la higiene pública y la asistencia social, la construcción de vías de comunicación, la organización de la educación nacional, el fomento de la agricultura y la cría, el establecimiento de una política fiscal y comercial, la política de inmigración y colonización. Sin embargo, se evadían dos temas esenciales, el petrólero y la política exterior, sobre los cuales es probable que el acuerdo fuese más difícil. El Programa de Febrero se alejaba, en este sentido, del Plan de Defensa Económica elaborado en 1918 por otro de los protagonistas del grupo, César Zumeta, entonces embajador en Estados Unidos, ${ }^{27}$ cuando terminaba la primera guerra mundial, y luego de afirmar que "lo único que de esta guerra importa es lo que vendrá después". En la carta que acompañaba al plan alertaba al presidente Gómez en estos términos:

${ }^{26}$ Véase López Contreras, Gobierno, 1966, pp. 16-30. Sobre la cuestión de la autoria directa del Programa de Febrero, se enfrentan Tomás Polanco Alcántara, quien se la asigna a Fscalante, y Tulio Chiossone, que se la otorga a López Contreras. Véase Chiossone, Decenio, 1989, pp. 57 y 152; Polanco Alcántara, Pluma, 1982, pp. 133134; Polanco Alcántara, General, 1985, pp. 156. 165. El Programa de Febrero fue criticado en su momento por ser "un programa blanco para una democracia mulata". Véase Penzini Hernández, Democracia, 1939 , p. 482.

${ }^{27}$ Véase Zumeta, Defensa, 1918, pp. 281 . 292. 
General, comienza la más tremenda guerra económica. Las naciones mayores necesitan pagar sus fabulosas deudas y calmar sus problemas sociales con to que produzca su industria, y se preparan a no importar sino lo que no puedan producir; a defenderse contra la invasión del capital y la industria de sus rivales; a explotar mercantil, industrial y financieramente los mercados extranjeros $[\ldots]$ se organiza cada nación $[\ldots]$ sin más política que la de obtener fuentes de materias primas para sus industrias, abaratar su producción y ensanchar cada día más su comercio exportador. No hay manera de eximirse en esta lucha. Los que pierdan serán dependencia de los que triunfen. ${ }^{28}$

De más está decir que el alerta, fechado el 27 de octubre de 1918, no tuvo la resonancia adecuada en la política de concesiones petroleras que se desarrollaría poco después, ni era previsible, en ese momento, el papel que jugarían las exportaciones venezolanas. Lo cierto es que, en la Sociedad de las Naciones, Zumeta, Escalante, Gil Fortoul, Parra Pérez, tuvieron la oportunidad de madurar, durante el periodo de entreguerras, un proyecto de modernización para cuando la realidad política venezolana fuese propicia. Contaron para ello, también, con las aproximaciones que fueron aportando sobre ella los más jóvenes funcionarios, como Alberto Adriani o Manuel Egaña (1900-1985), incorporados a la delegación durante los últimos años del gomecismo. Es en este conjunto de circunstancias, y de personajes, en don-

\footnotetext{
${ }^{28}$ Véase Pensamiento, 1983, siglo $\mathrm{xrx}$, tomo III, vol. I, p. 503.
}

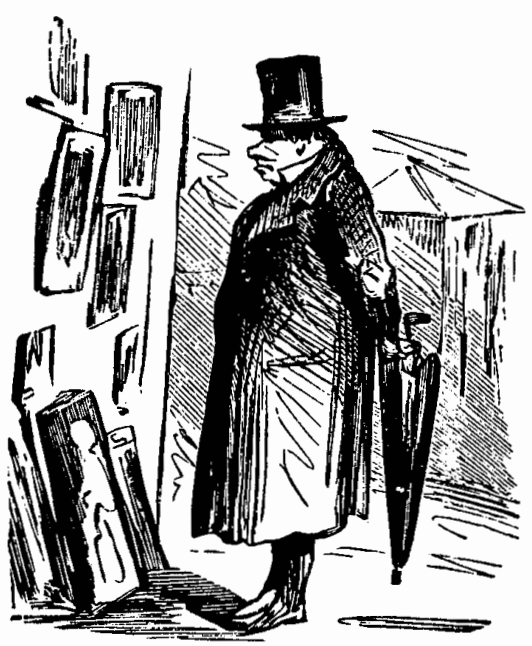

de debe buscarse la explicación a la rapidez con la que el programa requerido fue formado, los primeros días de febrero de 1936, por el nuevo presidente para darle credibilidad política y económica a su gobierno, amén de estabilidad.

En la reorganización del gabinete del 8 julio de 1936, Régulo Olivares (1873-1952), otro compañero del Colegio de El Sagrado Corazón de Ia Grita, asumió el Ministerio de Relaciones Interiores, mientras que Rómulo Gallegos fue sustituido en el de Instrucción Pública por el ingeniero Alberto Smith (1861-1942). Alejandro Lara (1874-1972), el autor del proyecto de una controvertida Ley de Orden Público y Social, pasó de Relaciones Interiores a Comunicaciones, y Santos Dominici (1869-1954) se incorporó como ministro de Sanidad y Asistencia Social. 
Este gabinete poseía un componente liberal -Adriani, Smith, Dominici- que se mantuvo hasta febrero de 1937 -al fallecer Alberto Adriani en agosto de 1936. fue designado ministro de Hacienda Atilano Carnevali- para dar paso a otro que sería el responsable del endurecimiento de la actuación del régimen con la expulsión del país de un buen número de dirigentes políticos de izquierda. ${ }^{29}$ Tanta movilidad permite suponer, por parte de López Contreras, un manejo de sus gabinetes de acuerdo con las circunstancias del día a día, sacando e incorporando ministros en medio de una coyuntura de evidente fluidez política. Así, de los nuevos partidos que se crearon en esa coyuntura, López Contreras incorporó al gabinete: de la Unión Nacional Republicana, fundada el 31 de enero de 1936, a Enrique Tejera y Alfonso Mejía; de la primera etapa del Movimiento de Organización Venezolana (ORVE), a Alberto Adriani; de la Liga de Defensa Nacional, a José Ramón Ayala; del Partido Nacionalista (PAR-NAC), a Tomás Pacanins, verdadero jefe del partido aunque el que figurase fuera su hermano Feliciano; del Partido Agrario Nacional, a Amenodoro Rangel Lamus, Manuel R. Egaña y Arturo Uslar Pietri. ${ }^{30}$

${ }^{29}$ Véase Fuenmayor, Historia, 1976, pp. 334-337 y 349-351.

${ }^{30}$ Véase Magallanes, Partidos, 1977, pp. 250-307. No fueron muchos los partidos fundados en esos años que permanecieron en el panorama político venezolano posterior. Buena parte de ellos aglutinaban intereses circunstan. ciales con el objetivo de ofrecer salidas a la inestabilidad política del país y confirmar un régimen democrático de libertades. Las coyunturas electorales que se desarrollaron, sobre todo a nivel municipal, los hicieron desapare-
Pero en el gabinete del 1 de enero de 1936, y en los siguientes, no sólo se encontraban los ex alumnos de La Grita y aquellos que en mayor o menor grado habían contribuido a la concepción y formulación del programa de gobierno de López Contreras. Estaban en él tres ministros sin vínculos con el régimen gomecista: José Ramón Ayala (1881-1966) en Instrucción Pública; Gustavo Herrera (1890-1953) en Hacienda, y Tomás Pacanins (1891-1958) en Obras Públicas, y que lograron sortear con éxito la primera gran remezón política del régimen en febrero del 36. De ellos, el que aquí nos interesa, Tomás Pacanins, estuvo más de dos años al frente del Ministerio de Obras Públicas. Durante ese periodo, el gobierno pasó del ideario políticoadministrativo del Programa de Febrero a su primera formulación presupuestaria en el Plan Trienal, de mayo de 1938. En ese tiempo, el MOP debía, tal como lo anunció López Contreras en su alocución del 21 de febrero de 1936, además de construir las obras esbozadas en el programa, formular y poner "en ejecución las que satisfagan la necesidades del país en otros aspectos" ${ }^{31}$ Era este el visto bueno que $\mathrm{Pa}$ canins necesitaba para emprender una transformación del ministerio, tanto en sus estructuras técnico-administra-

cer, y sus miembros se insertaron en los partidos llamados "modernos" por Magallanes: Acción Democrática, Comité de Organización Política Electoral Independiente (COPEI), Partido Comunista de Venezuela y Unión Republicana Democrática.

${ }^{31}$ Véase López Contreras, Gobiemo, 1966, p. 30 (cursivas mías) 
tivas como en los alcances sociales y económicos de sus funciones.

\section{Los otros aspectos}

Durante las tres primeras décadas de vida republicana las obras públicas apenas lograron pasar, en los mensajes presidenciales, de unas líneas dedicadas a las mejoras de los caminos y alguna que otra referencia a la insalubridad pública, sin que se apuntase en ellas la forma para enfrentarla. "Caminos e inmigración: he aquí la más hermosa ofrenda que podéis tributar a Venezuela", era el consejo del presidente José Tadeo Monagas al Congreso Nacional en 1856, para en seguida insistir:

los caminos son las arterias por donde circula la vida de los pueblos: todo estorbo, todo inconveniente en punto a comodidad y velocidad de los transportes, paraliza y desconcierta encareciendo, aun en nuestros propios mercados, mil preciosas producciones que de otra manera bastarían a constituir nuestra riqueza nacional. ${ }^{32}$

Pero en esos años no estaba muy claro todavía quién debía asumir la responsabilidad del fomento: si las sociedades privadas de participación o el Estado; 33 ambigüedad que arrastraba 224.

${ }^{32}$ Véase Monagas, "Mensaje", 1856, pp. 223-

${ }^{33}$ A este debate contribuyeron, durante todo el siglo $\mathrm{xIX}$, autores como Cecilio Acosta, Domingo Briceño y Briceño, Fermín Toro, Santos Michelena. Tomás Lander, Antonio Leocadio Guzmán, o Juan Bautista Calcaño, entre otros. Para entresacar sus posiciones es necesario recurrir a la colección Pensamiento políti- también, con toda naturalidad, la presentación del interés privado como el interés general. ${ }^{34}$ Con la creación, primero del Ministerio de Fomento en 1863, y luego del Ministerio de Obras Públicas en 1874, quedaron formalizadas las competencias en la materia. Modernización, progreso, fomento económico y tecnológico, rapidez y economía en el transporte, utilidad común, fueron las claves de los discursos y las actuaciones durante el poco más de un siglo de existencia del MOP (18741976). En ese tiempo, lo normal ha sido asociar a las obras públicas con las necesidades prioritarias para el "desarrollo moral y material" de la nación, sobre todo desde que, en 1911, Román Cárdenas (1862-1950) definiese por primera vez al MOP como el ministerio

co venezolano del siglo $X X X$. Textos para su es tudio, en especial los volúmenes 10,11 y 12. Sobre la agrupación entre "liberales" y "conservadores", además de comparar los textos seleccionados, véanse los estudios introductorios de Elías Pino Iturrieta e Inés Quintero en los volúmenes Pensamiento conservador del siglo $X I X$ y Pensamiento liberal del siglo XIX.

${ }^{34}$ Un buen ejemplo lo constituye el discurso de Manuel Felipe de Tovar al Congreso, en 1860, cuando estaba encargado del ejecutivo, exhortando a la protección que "demandan nuestras vías de comunicación, hasta lograr en este ramo, siquiera la ejecución de algunos ferrocarriles que despierten entre nosotros el espíritu del progreso material", para revitalizar, sin nombrarla, a la quebrada Colonia Tovar, asentamiento de inmigrantes alemanes en sus tierras. Véase Tovar, "Mensaje", 1860, p. 260. La valo rización de las tierras de la familia Tovar había sido iniciada, en 1834, por la Sociedad Empresaria de la Provincia de Caracas, de la cual eran accionistas, con la construcción de la carretera Caracas-La Victoria. Véase Camacho, "Venezuela's", 1984, pp. 279-289. 
del desarrollo, al inicio de su primera transformación. ${ }^{35}$

\section{Contra el desempleo}

Sin embargo, la construcción de obras públicas no ha sido la única razón de ser del MOP a lo largo de su historia. En 1886, el presidente Joaquín Crespo (1841-1898) lo explicaba con toda claridad en su Mensaje al Congreso, al dar cuenta de que había duplicado lo invertido en obras públicas el año anterior:

El excedente de gastos a que aquí me contraigo, tiene como sencilla explicación la dura alternativa en que se vio colocado el gobierno, de abandonar muchas obras contratadas de antemano y en las cuales se habían hecho erogaciones de no poca consideración, o continuar aquéllas aun a riesgo de exceder las limitaciones del presupuesto. Opté por este último extremo, impulsado además por el generoso deseo de dar ocupación a millares de venezolanos, que por causas imprevistas y prácticamente insalvables, se vieron en la necesidad de dejar desiertos sus campos, $y$ ocurrieron al gobierno demandando protección en tan critica emergencia. No consideré discreto desoír el clamor de las masas arruinadas por la inclemencia de las estaciones y por la terrible plaga de la langosta, y entonces me decidí a impulsar los trabajos públicos para dar honesta ocupación a los que con justicia la pedían. Estimé como deber del gobierno salvar al país de las desastrosas consecuencias de la miseria. ${ }^{36}$

${ }^{35}$ Véase Cilento y otros, "Dispositivo", 1999.

${ }^{36}$ Véase Crespo, "Mensaje", 1886, p. 290 (cursivas mías).
La construcción de obras públicas quedaba también instaurada como parte del engranaje económico del país, como un plan de emergencia que le daba al ejecutivo la posibilidad de resolver por ese medio problemas de empleo, de mostrar una arista filantrópica y de aquietar malestares sociales no deseados por el peligro que pudiesen encerrar en la alteración del orden público. Años después, durante el mandato del presidente Cipriano Castro (1858-1924), mientras éste arremetía contra la ya entonces costumbre de usar y saquear la hacienda pública -"hasta hacer válida y natural la vergonzosa teoría de que los empleados oficiales no son funciones de honra y de servicio bien intencionado a la república, sino brechas abiertas al Tesoro Nacional"- $-{ }^{37}$ el MOP justificaba la creación de puestos de trabajo con el fin de atender "a las necesidades de la clase trabajadora del pueblo que busca en ellos labor honrada en que emplear sus energías y justa compensación que asegure su bienestar y el sustento de sus familiares". ${ }^{38}$

Durante el régimen gomecista, el MOP fue capaz de consolidar su actuación sin necesidad de que aumentase su presupuesto. Con la profunda reorganización interna adelantada por Román Cárdenas desde 1910, que incluyó la creación de una sala técnica, el ministerio pudo afrontar los proyectos y la ejecución de las obras, en especial el plan de construcción de carreteras. Para ello, el mismo Cárdenas aseguró,

\footnotetext{
${ }^{37}$ Véase Castro, "Mensaje", 1904, p. 363.

${ }^{38}$ Véase Ministerio de Obras Públicas (en adelante MOP), Memoria, 1902, p. 5 .
} 
desde 1913, la continuidad de esta política de obras públicas gracias a la reforma de las finanzas del Estado que emprendió desde el Ministerio de Hacienda. Su permanencia en este ministerio hasta 1922, y la de Luis Vélez (c. 1860-1935) en el MOP hasta la misma fecha, fueron claves para un éxito técnico-administrativo poco común; éxito asentado a su vez en una implantación regional del ministerio acorde con el programa de construcciones. Sin embargo, entre 1908 y 1919, el presupuesto del MOP nunca fue superior a $10 \%$ del presupuesto nacional, superando apenas esta tasa a partir de 1927, momento en el que el ingreso fiscal proveniente del petróleo se reflejó significativamente en las cuentas públicas. ${ }^{39}$ Cuando en 1934 Juan Vicente Gómez anunció en el Congreso que el 19 de diciembre de 1933 dos comisiones, una desde Ciudad Bolívar y otra desde San Antonio del Táchira, habían llegado en automóvil a Maracay "en menos de 18 horas", Luis Vélez era nuevamente el ministro de Obras Públicas. ${ }^{40}$ Para esos años, en los que el crecimiento de los ingresos petroleros iniciaba un ascenso sostenido, el MOP se había consolidado como ministerio del desarrollo, apoyado tanto en su estruc-

${ }^{39}$ Véase Martín Frechilla, Planes, 1994, pp. 151-155; Arcila Farías, Centenario, 1974, pp. 203-225.

${ }^{40}$ Véase Gómez, "Mensaje", 1934, p. 264. Las ciudades están situadas: San Antonio en la frontera con Colombia, en el estado Táchira, al sureste; Ciudad Bolívar a orillas del río Orinoco, en Guayana, al sur, y Maracay en el centro norte del pais. La distancia aproximada entre San Antonio y Ciudad Bolívar es, en la red de carreteras actual, de 1300 kilómetros. tura organizativa como también en una parte, superior a $20 \%$, del presupuesto nacional. Vélez falleció unos meses antes que Gómez, pero entre 1933 y 1935, el ya anciano ingeniero tuvo como compañero en el gabinete a Eleazar López Contreras, ministro de Guerra y Marina desde 1931.

\section{Para calmar los ánimos}

No parece prudente desechar el papel jugado en esos años por el ministro Vélez a la luz de los primeros actos administrativos firmados por el general López Contreras como presidente encargado de la república, cuando todavía las palabras orden, paz, cordura, calma y fe estaban en boca de todos -no sólo de él-y antes de que las manifestaciones urbanas y los incendios y saqueos en las fincas rurales proliferasen como voluntad popular de confirmar su antigomecismo. ${ }^{41}$ Ocho fueron los decretos de obras públicas firmados por López Contreras, el 21 de diciembre de 1935: un liceo moderno para Caracas, una escuela de artes y oficios para cada capital de la república y escuelas rurales en cada distrito,

\footnotetext{
${ }^{41}$ El 19 de diciembre, López Contreras decía: "el momento demanda una gran cordura y un profundo sentimiento de solidaridad en pro del orden público", mientras que el $20 \mathrm{de}$ diciembre un grupo de venezolanos de izquierda escribía, luego de visitarlo en Maracay, un comunicado "Al pueblo de Caracas", en el que se le exhortaba a "comportarse con la mayor cordura", a no exteriorizar su impaciencia en forma violenta, pidiendo "calma y $\mathrm{fe}$ ", ya que "de nuestra serenidad depende el orden público". Véase Pensamiento, núm. 17, pp. 33-37.
} 
nueva sede para el Ministerio de Obras Públicas, ampliación del acueducto de la capital, acueductos para otras ciudades, y ampliación y reformas del balneario público de Macuto cercano a Caracas. ${ }^{42}$ Tal variedad de tipos de obra, y de localización geográfica, no deja de sorprender, cuando la llegada triunfal a Caracas de López Contreras y la ofrenda de rigor al Libertador Simón Bolívar en el Panteón Nacional apenas había sido el día anterior. Pero, sobre todo, sorprende porque en la mañana del 21 de diciembre el presidente encargado había recibido, en el Ministerio de Guerra y Marina, al general Eustoquio Gómez -primo hermano del presidente fallecido- horas antes de ordenarle al gobernador del Distrito Federal, Félix Galavís, que lo detuviese y expulsase del país, para liquidar con un solo acto unas aspiraciones presidenciales inconvenientes y mostrar cierta ruptura con el antiguo régimen. El confuso desenlace mortal ocurrido horas después en la Gobernación durante el arresto, ${ }^{43}$ contrasta con la indiscutible muestra de normalidad que se desprende de los decretos de obras públicas -firmados presumiblemente en la tarde de ese azaroso día- y la abundante exposición de motivos que los acompaña. Se confirman así, además del efecto político, los diversos objetivos que las obras públicas tendrían, sobre todo a lo largo de 1936: "El despacho de Obras Públicas, como órgano del ejecutivo federal, cumple la parte que le incumbe en el progra-

\footnotetext{
42 Véase Pensamiento, núm. 18, pp. 17-29.

${ }^{43}$ Véase López Contreras, Páginas, 1944, pp. 244-246.
}

ma del actual gobierno, desde tres puntos de vista: social, administrativo $y$ técnico". ${ }^{4}$

\section{La nueva nómina}

El clima social, que no podía ser ajeno a estas comprensibles y enconadas turbulencias, iba a ser percibido por la población como si se hubiesen disuelto los controles policiales y la represión hubiese bajado la guardia, aunque en la práctica no siempre fuese así. Esta coyuntura inicialmente permisiva, este "vacío de poder", movilizó hacia las ciudades, y en especial hacia Caracas, a grandes masas de población que se sumaron con todo entusiasmo a la descarga social antigomecista y a los saqueos de los bienes de los funcionarios más visiblemente identificados con el régimen anterior. De modo que las inversiones en obras públicas fueron, dentro de este proceso, además de un catalizador social y regional, un acelerador efectivo en la resolución de conflictos, similar a lo ocurrido en el país en otras coyunturas. El Ministerio de Obras Públicas fue el eficaz brazo ejecutor de una política de empleo apoyada en el sector de la construcción, amortiguadora del creciente desempleo urbano. El amplio plan de obras públicas -carreteras, puertos, acueductos, hospitales, escuelas y liceos, puentes, represas-, enunciado en el Programa de Febrero, cumplió cabalmente con este objetivo. p. 295 
Para todo ello fue necesaria la reorganización del MOP. Al respecto, en julio de 1936 Tomás Pacanins presentó un informe al presidente con el fin de acallar las críticas de sus propios colegas del gabinete sobre las decisiones técnico-administrativas, y sobre todo políticas, que había tomado desde su nombramiento en enero de ese mismo año. ${ }^{45}$ Aunque el ministro iniciaba el informe asegurando que no deseaba hacer referencia a las irregularidades en que habían incurrido sus antecesores en el despacho de Obras Públicas, al final sucumbe a la tentación:

Quiero y debo poner de manifiesto el completo desorden y la ausencia total de método que encontré en todas las oficinas del despacho que se me confió $[\ldots]$

Las atribuciones ilimitadas que se concedían por favoritismo o por connivencia con algunos empleados de obras públicas, la percepción ilícita de comisiones en los contratos y compras hechas al comercio interior y exterior $y$ el nepotismo llevado a un extremo desmedido, eran otros tantos males que obstaculizaban el funcionamiento normal del ministerio y propiciaban la malversación de los fondos destinados a las obras y la mala ejecución de las mismas.

En la parte técnica el personal idóneo debidamente preparado había sido desplazado, y se empleaban individuos faltos de los conocimientos y de la experiencia necesarios, sustitución que

\footnotetext{
45 Véase Archivo General de la Nación (en adelante AGN-MAC), 1936, folios 41-55. Sobre conflictos dentro del gabinete entre los partidarios del Partido Nacionalista y del Partido Agrario Nacional, véase Fuenmayor, Historia, 1976, pp. 310-311.
}

se hizo según el capricho de los ministros o las imposiciones de la política.

El desorden administrativo y la falta de dirección capacitada se reflejaba en la desorganización de los servicios técnicos en el interior del ministerio. Las distintas oficinas invadían mutuamente sus atribuciones y funciones respectivas. Salvo casos excepcionales, las obras públicas se ejecutaban sin haber sido estudiadas previamente desde el doble punto de vista técnico y económico, y se distribuían en el territorio de la república sin tomar en consideración las verdaderas y legítimas necesidades de la nación.

A mi llegada al ministerio no existía, pues, ni proyecto alguno para cada obra en particular que se pudiera tomar en cuenta, ni mucho menos un plan gene. ral que sirviera de norma. ${ }^{46}$

A estas descalificaciones por la improvisación técnica y el despilfarro económico, el desorden administrativo y la ausencia de método, que sin duda estaban marcadas por la necesidad de una nueva modernización del ministerio, había que agregar los ingredientes claramente políticos, que hacían necesario el deslinde con el régimen gomecista. ${ }^{47}$ La construcción de obras públicas había permitido la gestación de tempranos quistes burocráticos; gestación de gestores de contratos y comisiones en un proceso de ampliación de la estratificación administrativa, de evidente socialización de las oportunidades. Estos ilícitos ampliaban el favoritismo, - la pura y simple malversación, que llegaba a poner en peligro la calidad

\footnotetext{
46 Véase AGN-MAC, 1936, folios 41-42.

47 Véase Cilento y otros, "Dispositivo", 1997.
} 
de las obras, al tiempo que subrayaban una falta de equidad territorial de raíz clientelar.

Pero esta enumeración de las irregularidades técnico-administrativas encontradas en el MOP era el preámbulo escogido por Pacanins para poder exponer y justificar lo que sería clave en la actividad del ministerio durante los primeros meses de 1936, y su utilidad primordial para la estabilidad del régimen:

debo detenerme en la situación conflictiva que el gobierno nacional confrontó a raíz de la muerte del general Gómez, cuando el ciudadano presidente reorganizó su gabinete y tuvo a bien designarme para el cargo que ocupo. Fueron aquellos momentos excepcionales en la vida política y económica de la nación porque el pueblo, en posesión repentina de una libertad que no había conocido, ejerció ésta antes que todo para pedir justicia y pan. Pueblo necesitado, hambriento, casi al límite de la desesperación, pedía trabajo y solamente dándole trabajo era posible detener la anarquía sin requerir a medios extremos cuyo empleo repugnaba al ejecutivo. Era preciso darles el trabajo que reclamaban, y la urgencia con que este ministerio atendió dicha exigencia correspondió a la gravedad y a la fuerza del clamor.

En esas circunstancias de perentoriedad el Ministerio de Obras Públicas dio ocupación a más o menos 40000 obreros en vez de 6500 que trabajaban para ese momento en las diversas obras en ejecución, y por fuerza tuvo que confrontar el problema que significaba el exceso de brazos disponibles y los altos tipos de salario que se había adoptado con anterioridad. [...] no se pudo dedicar estos hombres a un trabajo verdade- ramente útil y se les ocupó en el Distrito Federal $[\ldots]$ es preciso reconocer y así queda enfáticamente afirmado, que la magnitud de lo hecho en los primeros meses no guarda proporción con los gastos, pero debe tenerse muy en cuenta que se obedeció a una necesidad política, y no se tuvo por objetivo principal la obra en sí [...] lo esencial, lo inmediato, era que los desempleados pudieran llevar pan a sus hogares, que el pueblo cobrase confianza y adhesión a un gobierno que a ojos vistas se preocupaba por sus angustias y sus miserias. Era además urgente restablecer el orden, terminar con una agitación que se hacía peligrosa, pues podía llevar a las masas a la comisión de actos de violencia y de terror, y eso se logró. ${ }^{48}$

Estos son los argumentos que potenciaron en el MOP unas funciones, distintas a las propiamente constructivas y de planificación física, que no serían abandonadas desde entonces y hasta su liquidación en 1976, a pesar de los altibajos coyunturales, de raíz fiscal o política de la historia del país.

\section{Recelos y resistencias}

En 1936, el propio gabinete no aceptaba que recayese en el MOP la tarea de enfrentar el problema del desempleo, en buena parte por el poder político que ello encerraba. Tomás Pacanins, aunque aseguraba que esa política era provisional y estaba en vías de normalizarse, se quejaba ante el presidente de los frecuentes ataques de sus colegas contra su gestión, por "la despro-

${ }^{48}$ Véase AGN-MAC, 1936, folios 43-44. 
porción entre el dinero gastado y el rendimiento útil obtenido".

Desde la creación, el 25 de febrero de 1936, del Ministerio de Agricultura y Cría (MAC), y la designación de Alberto Adriani como ministro en la reorganización del gabinete del 2 de marzo, la cuestión agraria confirmaba la importancia que se le había asignado en el Programa de Febrero. ${ }^{49}$ Fue esta coyuntura la que obligó al MOP a "reducir los presupuestos de las obras por razones del reajuste imperativo de las finanzas". Sin embargo, para evitar brotes de malestar que pudiesen generar desórdenes, Pacanins recurrió a la semana de cinco días, a una reducción del tipo de salario para armonizar "los jornales de obras públicas con los que puede pagar la agricultura y la cría", y a "la creación de colonias agrícolas con el fin de evitar la aglomeración de desocupados en las ciudades"; colonias adscritas después al Ministerio de Agri-

49 El traslado de Adriani al Ministerio de Hacienda, en la reestructuración de gabinete del 8 de julio de 1936, lejos de constituir un quiebre en este objetivo lo refuerza. Alfonso Mejía, quien lo sustituye, proviene de la Unión Nacional Republicana, en cuya plataforma programática se destaca en solitario el relativo a la cuestión agraria. Véase: Magallanes, Partidos, 1977, p. 253. En el núm. 1 de la Revista de $\mathrm{Ha}$ cienda, fundada por Adriani, se publican sin título unas notas encontradas entre sus papeles que comienzan así: "desde el punto de vista financiero, el programa de febrero pide un sistema tributario más rediticio, más equitativo, más justo". Véase Adriani, "Nota", 1936, p. 7. Pareciera que se reproduce aquí un traslado similar al efectuado por Gómez cuando, una vez formulada la política de obras públicas, trasladó a Román Cárdenas al Ministerio de Hacienda para asegurar los fondos necesarios. Recordemos que Adriani falleció en agosto de 1936. cultura y Cría. ${ }^{50}$ Este "cara a cara" entre el MOP y el MAC tuvo también un poso político importante. En agosto de 1937, a un año de la muerte de Adriani, el Partido Agrario Nacional afirmaba, al fundarse, un modelo de país: "la economía venezolana debe ser típicamente agrícola y pecuaria". ${ }^{51}$ Por su parte, Tomás Pacanins, que había estudiado la secundaria en una escuela militar en Estados Unidos, país en el que, después, se había graduado de ingeniero eléctrico, provenía de un universo económico y político distinto. Su propio desempeño profesional desde 1912 y su ascendiente sobre su hermano menor, Feliciano Pacanins (1895-1975), conectado al mundo de la banca, marcaban las diferencias sobre el modelo de país definido en el programa del Partido Nacionalista. ${ }^{52}$ No es de extranar, entonces, que fuese el Ministerio de Agricultura y Cría el que presentase al gabinete un "Proyecto de Lucha contra el Desempleo en Venezuela":

${ }^{50}$ Véase AGN-MAC, 1936, folio 45; MOP, Memoria, 1937, p. XII.

${ }^{51}$ Para el programa del Partido Agrario Nacional y otros documentos, véase Pensamiento, núm. 32, pp. 261-310. El manifiesto inicial lo firman, entre otros, Arturo Uslar Pietri y Manuel R. Egaña; para ese momento, el ministro de Agricultura y Cría es Amenodoro Rangel Lamus, mentor principal de dicho partido, $y$ antes secretario de la presidencia. Véase Magallanes, Partidos, 1977, pp. 305.307. Egaña, quien sería el último ministro de Fomento de López Contreras, evolucionaría hasta poner en duda, para Venezuela, las posibilidades de una economía basada en la agricultura. Véase Egaña, Reflexiones, 1988.

\$2 Abundante material sobre las relaciones de los hermanos Pacanins con la banca, en Pacanins, 51 años, 1970. Sobre el Partido Nacio. nalista, véase Pensamiento, núm. 31, pp. 161- 


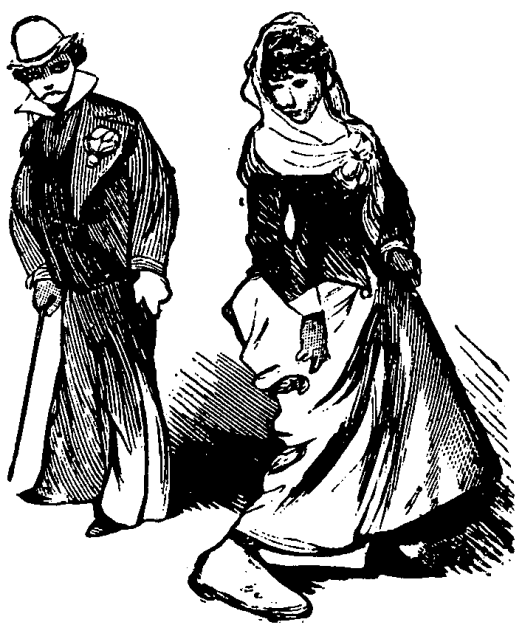

Seguramente que desde la más remota antigüedad, fue el desempleo un verdadero problema para los gobiernos, cuando sabemos de esas monumentales obras de la antigüedad: las pirámides, las dilatadas murallas de muchas ciudades, etc., etc., no podemos menos que pensar que estas obras fueron el resultado del exceso de brazos a los que se buscó aplicación para justificar su manutención y remuneración. [...] En algunos países, especialmente en Inglaterra, se trató de ayudar a los sin trabajo dándoles pensiones alimenticias, pero esta práctica fue nefasta. ${ }^{53}$

Ni es de extrañar tampoco que el informe arremetiese, como lo hacía, con-

168. Mientras el grupo "agrario" publica "Sembrar el petróleo" como editorial sin firma en Abora, el 14 de julio de 1936, Henrique Pérez Dupuy, del grupo "industrial", escribe "Sembrar petróleo" en La Esfera, el 4 de mayo de 1939.

${ }^{53}$ Véase AGN-MAC 1936, sin foliar. tra la política seguida por el Ministerio de Obras Públicas:

sin duda que el método adoptado con este fin hasta ahora: emplearlos en las obras públicas nacionales, no puede ni debe ser seguido, desde el momento que el Ministerio de Obras Públicas no tiene por misión acabar con el desempleo, sino la ejecución de obras de ingeniería necesarias al desarrollo, salubridad y ornato del país, con métodos científicos, económicos y dentro de la capacidad técnica y del presupuesto del departamento, no debiendo, por tanto, continuar el aumento de su personal obrero, ni la prosecución de obras con el solo fin de dar trabajo a los desocupados, sino que por el contrario, debe limitarse a utilizar los obreros capaces e indispensables para la mejor ejecución de cada obra debidamente proyectada y estudiada con un plan determinado y económico.

Para finalmente ofrecer como solución el desarrollo de la agricultura exponiendo un plan factible, siempre $y$ cuando, "al igual que en los Estados Unidos de Norte América", se expulsasen del país "a los extranjeros que no sean agricultores" y se eliminasen "de todos los trabajos de construcción del gobierno o de particulares a los que no sean venezolanos". Sin embargo, a pesar de las críticas, las "urgencias" de 1936 inclinaron la balanza, por un tiempo, hacia la política seguida por Pacanins contra el desempleo. ${ }^{54}$

${ }^{54}$ El escritor y periodista Enrique Bernardo Núñez, al hacer, en julio de 1936, un balance del primer semestre del gobierno de López Contreras, critica la "superproducción de leyes" mientras "una tribu hambrienta" permanece en 
La Liga Nacional de Desempleados, en la que militaban "más de 2000 sin trabajo", según un volante fechado el 21 de mayo de 1936, es una muestra de la matriz de opinión favorable a la política del MOP. Este documento, titulado "La Liga Nacional de Desempleados alerta al noble pueblo de Caracas" parece, por su tono $-y$ la coyuntura-, redactado por el gobierno, en general, cuando dice: "sostener a todo trance la buena armonía", "sólo en el seno del orden, de la paz, hallan favorable solución los más arduos problemas" que deben ser "tratados y estudiados en el seno de la armonía, con patriotismo y cordura", y por Pacanins en particular, al abogar a favor de "las urgen. cias del Ministerio de Obras Públicas" amenazado por un "déficit de varios millones de bolivares", problema éste que corría el riesgo de no resolverse si cesaba en sus funciones el Congreso. ${ }^{55}$

\section{El nuevo ministerio}

El aumento ya señalado en la nómina de obreros del MOP requirió de una transformación radical en la organización administrativa y en el control

"el patio del Capitolio, donde pueden verse los efectos de este terrible fenómeno que es la miseria nacional: una multitud de mendigos, gente desarrapada, viudas, niños, pobres vergonzantes, estacionada horas y horas ante las oficinas del Congreso, en espera de una limosna", véase Núñez, Primer, 1936, pp. 371-372.

55 Véase Pensamiento, núm. 31, pp. $117-$ 118. En medio de paros contra el proyecto de Ley de Orden Público y Social, la oposición solicitaba ese mismo día 21 de mayo, en el Teatro Nacional, la disolución del Congreso gomecista y la convocatoria a elecciones

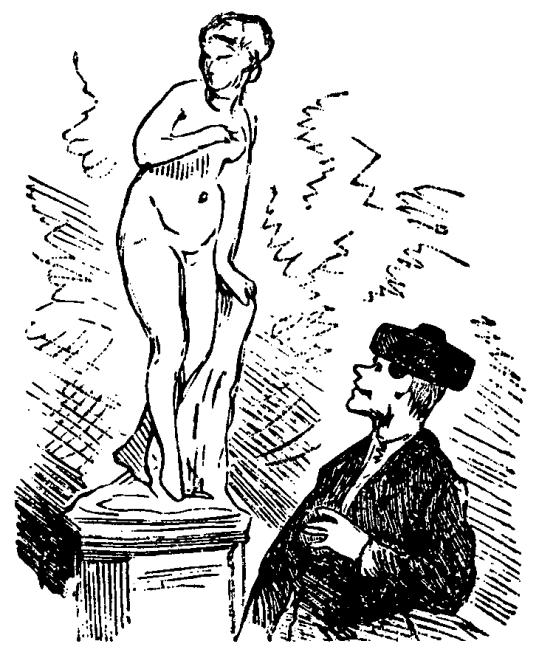

técnico de las obras, así como del personal contratado para ejecutarlas en todo el territorio nacional. ${ }^{56}$ De modo que el ministerio, además de los procedimientos para licitación, para el seguimiento y el control de las construcciones, para el inventario de los materiales y los controles de entrada y salida de los mismos, emprendió la cedulación de todo su personal antes de que en el país fuese obligatoria la obtención del documento nacional de identidad. Esta

${ }^{56}$ El 19 de abril de 1936 López Contreras informó al Congreso: "Cuarenta mil hombres trabajan en las obras públicas nacionales. Tiene este ramo importancia tan excepcional para el progreso de Venezuela y el desarrollo de los planes politicos $y$ administrativos emprendidos y en estudio, que el gobierno no ha vacilado en prestarle su más decidido apoyo", véase López Contreras, "Mensaje", 1936, p. 285 (cursivas mías). 
cédula de identificación, obligatoria y gratuita para todo empleado del Ministerio de Obras Públicas, incluía, además de los datos personales del portador, su fotografia y la huella del pulgar derecho. La Oficina de Control de Pagos e Identificación del Personal puso en práctica también un sistema de chequeo de las asistencias por medio de la perforación de tarjetas. ${ }^{57}$

Para organizar el trabajo de los 40000 obreros, las distintas ramificaciones del Plan de Emergencia requirieron de una conducción técnica de indudable competencia. Sin embargo, esta organización consumía una "parte relativamente grande del presupuesto del ministerio". Pacanins lo justificaba diciendo que "no sería posible llevar a la práctica un plan científico y ordenado de obras ni realizar ciertos trabajos sin tener a la disposición un organismo que responda a las exigencias de la técnica y de la economía". Independientemente de cuanto de coartada política, o de argumento científico-tecnológico, pudiese haber en estos enunciados, lo cierto es que, para asegurarse de cumplirlos, Pacanins entronizó la planificación en el MOP. La utilizó para validar la jerarquización de las inversiones -por tipos de obras y por distribución territorial- y para "impulsar la formación de compañías constructoras venezolanas, cuya capacidad técnica y cuya eficiencia y responsabilidad vayan mejorando progresivamente". Esto último, a fin de que el MOP pudiese abandonar la administración directa por la contratación de obras a empresas na-

\footnotetext{
57 Véase AGN-MAC, 1936, folios 71-73.
}

cionales por licitación, propiciar en el país la fundación de industrias de nuevos materiales de construcción, fomentar el empleo creciente de maquinaria, abaratar las obras y establecer un moderno "equilibrio económico entre la técnica y el trabajo". ${ }^{58}$ Con este ideario, preparado en julio de 1936, se cristalizaba en el MOP la aspiración de Román Cárdenas en 1909, ahora reforzada por la experticia profesional anglosajona de Tomás Pacanins. Quedaban, sin embargo, pendientes otras iniciativas.

\section{SEGUNDA PARTE: LOS SERVICIOS SOCLALES}

A los quince días de estar al frente del Ministerio de Obras Públicas, Tomás Pacanins recibió una instrucción del presidente que se sumaría a los decretos de construcción de obras públicas y a la política de creación de empleo. Se trata, escribe López Contreras, de "un programa de mejoramiento moral y físico de nuestras clases laboriosas", cuyos términos eran los siguientes:

a los fines de combatir el analfabetismo de las clases trabajadores y de desarrollar en ellas el verdadero concepto de los deberes y derechos cívicos, desea [el presidente] crear, en cada campamento, no menor de cincuenta (50) hombres, ni mayor de cien (100), un cargo de profesor de instrucción primaria elemental para servicio nocturno.

Los respectivos maestros podrían dictar conferencias, en las cuales inculquen a sus auditores aquellos principios de moral cívica, indispensables para

${ }^{58}$ Véase AGN-MAC, 1936, folios 49-50. 
ilustrarlos sobre los propósitos que debe abrigar todo buen venezolano, alejándolos asi de las ideas malsanas que propenden a relajar el sentimiento patriótico y socavar los fundamentos de la sociedad.

También considera la conveniencia de establecer, por ese departamento, un servicio médico en cada lugar donde se concentre una agrupación no menor de doscientos (200) trabajadores, con botiquines y ambulancias para atender a la higiene de los campamentos y prestar el debido cuidado a los enfermos. Los servicios suministrados en hospitales y enfermerias correrán por cuenta del despacho a su cargo.

Para mayor eficacia de estas instituciones sanitarias, los médicos respectivos estarán en el deber de dictar conferencias, los días feriados, sobre higiene social, y muy especialmente para combatir el alcoholismo y estimular la previsión contra las diversas enfermedades que atacan a nuestra poblaciǒn. ${ }^{59}$

Tomás Pacanins respondió de inmediato al presidente-"compenetrado en absoluto con las ideas de su brillante iniciativa"- indicándole que se creaba de inmediato un departamento especial "destinado a ambos fines". Nacían, de este modo, los servicios de educación y de salud del Ministerio de Obras Públicas con el enunciado explícito de "ejercer una verdadera función social" y teniendo dos intereses fundamentales. Por una parte, el control de enfermedades, ya que "la eficiencia de nuestros obreros se perjudica muchísimo con el contagio constante de los centros urbanos" y, por la otra, la educación y el deporte, con el fin de que los

59 Véase MOP, Memoria, 1937, pp. 23-24. obreros empleen sanamente "las horas de asueto para evitarles la concurrencia a las cantinas y la consiguiente degradación física y moral". ${ }^{60}$

\section{Antecedentes}

Si bien es posible encontrar, a lo largo de todo el gobierno de Juan Vicente Gómez, la formalización a nivel nacional de las primeras trazas institucionales y legales del Estado venezolano en relación con la salud, la educación y el trabajo, ${ }^{61}$ no será sino durante los primeros meses de 1936 cuando se definan con mayor firmeza, tanto la legislación sobre estos temas como la estructura de la administración pública capaz de hacerla cumplir. La diversidad de las iniciativas, su articulación -nueva Constitución, nuevos ministerios, nuevas leyes-, habla a las claras de que no fueron sólo las presiones políticas las impulsoras de estos cambios, detrás estaban también los planes de modernización que habían ido forjando en el "exilio" ginebrino, como hemos visto, algunos de nuestros representantes diplomáticos al dejar de ser ministros del gobierno gomecista. Así, por ejemplo, en noviembre de 1911 se creó la Oficina Nacional de Sanidad como respuesta a las recomendaciones del Primer Congreso de Municipalidades de Venezuela (19 de abril al 31 de mayo de 1911), organizado por César Zumeta como ministro

${ }^{60}$ Véase AGN-MAC, 1936, folio 36.

${ }^{61}$ Véase Archila, Historia, 1956; Fernández Heres, Educación, 1994; Parra Aranguren, Antecedentes, 1965. 
de Relaciones Interiores, ${ }^{62}$ y del Primer Congreso Venezolano de Medicina (24 de junio al 4 de julio de 1911), coordinado por Luis Razetti. ${ }^{63}$ Esta oficina confirmaría sus funciones al promulgarse, en 1912, la primera Ley de Sanidad, elevando su rango institucional en febrero de 1936, al crearse el Ministerio de Sanidad y Asistencia Social en el que se incorporaron las atribuciones y las dependencias que se habían estructurado durante esos años. ${ }^{64}$

Por su parte, la cuestión laboral había estado regida, en el gobierno de Juan Vicente Gómez, primero por la Ley de Talleres y Establecimientos Públicos de 26 de junio de 1917 -en la que se remitía a la Ley de Sanidad con respecto a las condiciones que deberían tener los sitios de trabajo- ${ }^{65} \mathrm{y}$, después, por la Ley del Trabajo de 28 de julio de 1928 . $^{66}$ De modo que, amparado por el artículo $4^{\circ}$ de dicha ley, el gobierno de López Contreras creó, el 29 de febrero de 1936, la Oficina $\mathrm{Na}$. cional del Trabajo. La exposición de motivos decía:

los Estados modernos despliegan hoy una actividad administrativa especial para proteger a los obreros contra las

62 Véase Pensamiento, núm. 9.

${ }^{63}$ Véase Razetti, Obras, 1962 . Luis Razetti (1832-1832), médico, higienista, renovador de los estudios de medicina en Venezuela, uno de los fundadores de la cirugía moderna venezolana y pionero en la difusion del positivismo biológico en el país.

${ }_{64}^{64}$ Véase Recopilación, 1912, tomo xxxv, pp. 407-408.

${ }^{65}$ Véase Recopilación, 1917, tomo XI, pp. 165-166.

${ }^{66}$ Véase Recopilación, 1928, tomo LI, pp. 430-436. contingencias desgraciadas que para la salud, para su integridad corporal, para su bienestar económico o para su vida se pueden derivar, directa o indirectamente, del trabajo material por ellos ejecutado. $^{67}$

La Oficina Nacional del Trabajo, inicialmente adscrita al Ministerio de Relaciones Interiores de acuerdo con la Ley del Trabajo de 1928 , formaría parte, desde marzo de 1937, del nuevo $\mathrm{Mi}$ nisterio del Trabajo y de Comunicaciones. ${ }^{68}$

\section{Nueva legalidad}

Pero las instrucciones de López Contreras al ministro de Obras Públicas encontraron el marco adecuado en la nueva Ley del Trabajo y en la Constitución Nacional, ambas aprobadas por el Congreso en julio de $1936 .{ }^{69} \mathrm{La}$ Constitución estipulaba que la ley debía disponer de:

lo necesario para la mayor eficacia y estímulo del trabajo, organizándolo adecuadamente y estableciendo la protección especial que deberá dispensarse a los obreros y trabajadores para proveer al mejoramiento de su condición física, moral e intelectual, y al incremento de la población.

Y que, por otra parte, debía velar "por la protección social del obrero y del jornalero"; para finalmente insistir

${ }^{67}$ Véase Gaceta, 1936, núm. 18.893.

${ }^{68}$ Véase Recopilación, 1937, tomo IX, p. 184.

${ }^{69}$ Véase Gaceta, 1936, núm. extraordinario; Vilchez, Compilación, 1996, pp. 451-474. 
en que la legislación del trabajo debía, para "mejorar las condiciones del obrero", fomentar "la enseñanza técnica" de los mismos.

En la Ley del Trabajo quedaba establecido que el Estado, para efecto de "las obras o servicios públicos" que ejecutase (art. $2^{\circ}$ ), era un patrono. En las Disposiciones Generales, luego de garantizar la libertad de comercio en los centros de trabajo -"a menos que esta libertad resulte contraria a los intereses mismos de los trabajadores o a los de la colectividad"-, se prohibía taxativamente "el establecimiento de expendios de bebidas embriagantes, las casas de juegos de azar y las casas de prostitución" (art. 11). Esta prohibición debía ser efectiva "en un radio de tres kilómetros de los centros de trabajo ubicados fuera de las poblaciones" (art. 12). Pero es en el capítulo vi de la Ley De las Condiciones de Higiene y Seguridad Industrial, donde se encuentran las disposiciones que afectarían a la mayor parte de las obras públicas construidas en el territorionacional por el MOP. En la sección sobre los campamentos de trabajadores se establecía una normativa que el propio Estado debía cumplir, si bien era evidente que lo que los legisladores habian tenido en mente eran las empresas mineras, en especial las petroleras, y sus campamentos de explotación: cuando se diese ocupación a más de cien obreros en una obra situada a más de dos kilómetros de un centro poblado era obligatorio construir campamentos con habitaciones higiénicas de "cuando menos cuatro y medio metros cuadrados de superficie" por trabajador, y proporcionalmente mayor cuando se tratase de una fami- lia. Estos campamentos debían, además de estar provistos de agua potable, alumbrado y letrinas, "sostener a su costo una o más escuelas de instrucción primaria, gratuita y obligatoria" (art. 91). En el caso de que el número de obreros fuese superior a los 300 , y el campamento estuviese situado a más de diez kilómetros de un centro poblado, las obligaciones, en cuanto a la asistencia médica, aumentaban a un médico y un farmaceuta -"si el número de empleados y trabajadores" no pasaba de 400-, y a "un médico más por cada 400 empleados u obreros, o por una fracción mayor de 200" (art. 93). En seguida se establecía:

Estarán también obligadas las empresas a que se refiere este artículo, a construir en cada explotación uno o varios hospitales montados de acuerdo con los preceptos de la higiene moderna, con servicios de cirugía convenientemente dotados y con provisión de drogas necesarias y suficientes para atender a las necesidades habituales de las diferentes zonas.

Estas empresas deberán tencr un laboratorio de investigación dotado de todos los elementos útiles necesarios, a fin de poder fijar la naturaleza de las enfermedades reinantes.

Para velar por el cumplimiento de estas disposiciones, la Oficina Nacional del Trabajo podía contratar a los médicos e ingenieros necesarios (art. 154). Es así como, en agosto de 1936, creó en su seno un Servicio de Trabajo Agrícola, de Salarios y Costo de Vida y de Acción Social, que asumió entre sus atribuciones el control de los campamentos de trabajadores y la promo- 


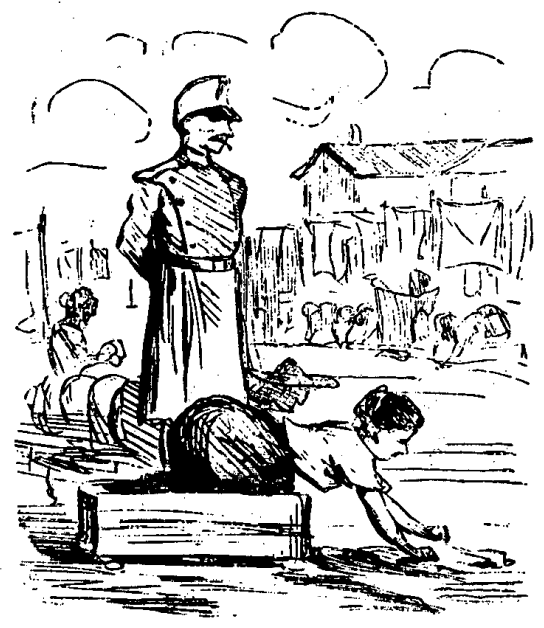

ción, junto con los ministerios de Sanidad y Asistencia Social, Fomento -al cual estaba adscrito el Banco Obrero-, y Obras Públicas, de un plan de construcciones y mejoramiento en las viviendas de los trabajadores. ${ }^{70} \mathrm{Sin} \mathrm{em}$ bargo, esta iniciativa en el campo de la vivienda obrera quedó limitada posteriormente al control de las construidas por las compañías petroleras en los campamentos, toda vez que a partir de la nueva Ley del Banco Obrero aprobada en septiembre de 1936 se ampliaron sus atribuciones. Ahora el instituto podía adelantar una reorganización interna para, sin perder la estructura ori-

\footnotetext{
${ }^{70}$ Véase Ministerio del Trabajo y Comunicaciones (en adelante MTC), Memoria, 1937. El Banco Obrero fue creado en 1928 con el fin de promover la construcción de viviendas para los trabajadores.
}

ginal de entidad bancaria, asumir un papel más directo en la construcción de urbanizaciones y viviendas "para la clase obrera y parte de la clase media pobre". ${ }^{71}$ Dentro de este marco legal e institucional, el Ministerio de Obras Públicas puso en marcha sus servicios sociales a fin de cumplir con una "verdadera función social" y contribuir a la "solución de los conflictos de carácter social" que presentaba el país. ${ }^{72}$

\section{Obreros sanos}

Así como en el campo de la construcción el MOP dispuso en 1936 de un grupo de profesionales de muy alto nivel, ${ }^{73}$ los nombres de los médicos, algunos todavía bachilleres, que aparecen como responsables y ayudantes de las distintas dependencias del Servicio Médico de Obras Públicas (SMOP), son igualmente relevantes. Sólo así se explica, en parte, la rapidez con la cual se monta en tan poco tiempo un dispositivo sanitario de indudable complejidad en su funcionamiento y alcances, e implantado en la casi totalidad de las obras públicas en ejecución por todo el territorio nacional. Un Informe, preparado en julio de 1936 por el SMOP para el ministro Pacanins, da cuenta de los objetivos, de las actividades y de la or-

\footnotetext{
71 Véase Ministerio de Fomento (en adelante MF), Memoria, 1937, p. 25.

72 Véase MOP, Memoria, 1937, pp. XII-XIV.

${ }^{73}$ Formaban parte de esa nómina: ocho futuros ministros de Obras Públicas, cinco futuros directores del Banco Obrero, además de los profesionales que durante los siguientes 30 años tuvieron un papel fundamental en el desarrollo de la ingeniería y la arquitectura venezolanas.
} 
ganización, tanto del dispensario "Villa Ignacia" en Caracas como del servicio médico en el interior de la república. ${ }^{74}$ En "Villa Ignacia", doce médicos, siete bachilleres-practicantes, cuatro enfermeras y 17 auxiliares -entre administración, economato, cocina y lavandería- tenían a su cargo la clínica externa, con consulta matinal y vespertina, el servicio de hospitalización y urgencias, los de traumatología, sífilis y vías urinarias, el laboratorio bacteriológico y los servicios de otorrinolaringología, oftalmología, odontología, farmacia y curas. Como es usual en estos dispositivos de salud, las estadísticas dan cuenta de la labor desplegada: en el mes de junio se trataron 550 enfermos de sífilis con alrededor de 3000 inyecciones, y en los cinco meses comprendidos entre febrero y junio de 1936 fueron atendidos 15000 obreros. Además de Caracas, el servicio médico fue implantado, durante 1936, en 22 sectores de obras públicas en todo el país; cada uno de ellos con un médico como responsable:

Esta asistencia médica se imparte a veces a peones agrupados en núcleos escalonados en extensiones casi siempre de centenares de kilómetros, a distancias de tres, cuatro, y aun más kilómetros, de esos grupos. Hay ramales muy complicados en las carreteras que obligan perentoriamente a recorridos entrecruzados y opuestos, lo que da lugar a viajes fatigosos de muchas jornadas por páramos, selvas o desiertos. ${ }^{75}$

\footnotetext{
${ }^{74}$ Véase AGN-MAC, 1936, folios 29-39.

${ }^{75}$ Ibid., folio 34 .
}

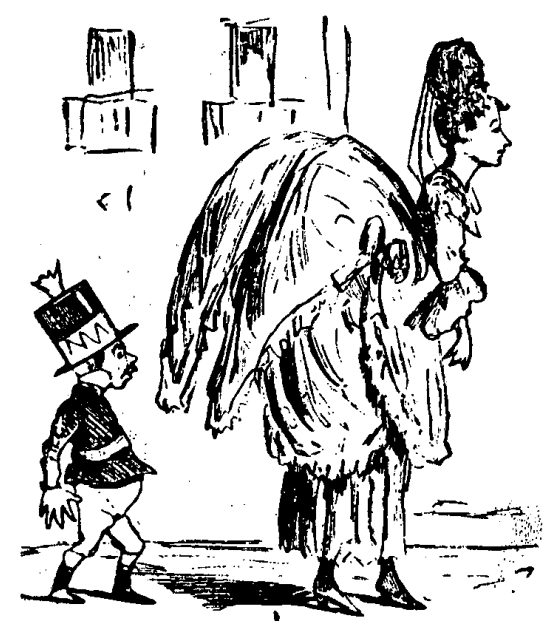

Pero el servicio de los médicos de carreteras del MOP tenía, junto con sus naturales propósitos en el campo de la salud, otros que subrayamos nosotros en el citado informe. Ellos son:

obtener el mayor rendimiento de los trabajadores de carreteras y demás obras nacionales. Es obvio que un personal en buenas condiciones físicas desarrolla una eficiente actividad en concordancia con el salario percibido. De aquí, igualmente, que el médico de Obras Públicas ha de ocuparse de afecciones crónicas, vigila con especial cuidado las enfermedades infecciosas que hagan peligrar la comunidad y se ocupa de accidentes, excluye al individuo inválido, evita el trabajo de niños o de seniles. Cuida de que el obrero se libre del paludismo, la anquilostomiasis, la tripanosomiasis, da conferencias de profilaxia de esas enfermedades y de las in- 
fecciones venéreas. Ordena la construcción de letrinas rurales. ${ }^{76}$

Para que las dificultades que afrontaban los médicos de carreteras por las precarias condiciones de trabajo fuesen superadas con entusiasmo apostolar, el MOP los seleccionaba entre los jóvenes recién graduados, o por terminar la carrera, solteros, aptos para vivir en campamentos, y les ofrecía la oportunidad de "trabajar fuera del medio hospitalario sin la tutela de un profesor". Ello les permitía valorar "su pers. picacia e iniciativa profesionales" en el campo curativo y en el de la prevención, al tener que impartir instrucción sanitaria en las campañas de propaganda antipalúdica, antivenérea y antiparasitaria, e infundir en "todas partes la preferencia de beber agua limpia y de no diseminar las deyecciones"; difícil cometido dadas a. las "inconveniencias y penalidades" de los campamentos. ${ }^{77}$

\section{Buenas costumbres}

Con la nueva Ley del Trabajo, la construcción de campamentos para alojar a los obreros y a los servicios médicos era vigilada por el SMOP, tanto por las condiciones higiénicas -tela metálica para proteger de los zancudos y excusados- como por el entorno en que eran localizados. Así, los médicos de

${ }^{76} \mathrm{Ibid}$, folio 33.

77 Véase AGN-MAC, 1936, folio 35. Entre 1936 y 1940, el gobierno de López Contreras invirtió $28.55 \%$ del total de obras públicas ejecutadas en la construcción de cloacas y acueductos urbanos. Véase Martin Frechilla, Planes, 1994, cuadro núm. 24, p. 279. carreteras se convertirían en los denunciantes, ante los ingenieros de las oficinas regionales del MOP, de las violaciones al artículo 12 de la Ley del Trabajo:

esta medicatura ha comprobado que en torno a los campamentos del "Amorador" existen varias casas de prostitución con el agravante de que sus pensionarias padecen enfermedades venéreas en el estado contagioso y que han transmitido a varios de nuestros obreros allá residenciados. Igualmente, la medicatura ha observado que en los establecimientos vecinos a dichos campamentos, se expenden bebidas embriagantes. ${ }^{78}$

Denuncias que, en algunos casos, parecen haber dado resultados satisfactorios:

En un principio acudían numerosos blenorrágicos y chancros tantos que los enfermeros no eran suficientes para hacer las curas y lavados necesarios. Hoy se presentan esporádicamente porque los focos de contaminación han sido alejados. Antes las prostitutas hacian su viaje de week end a lo largo de los campamentos, entregándose al mayor número de obreros posible, que a pequeñas contribuciones hacían un buen número de bolívares para costearles la semana. Estas mujeres, casi todas enfermas, contagiaban fácilmente a los obreros que no saben nada de profilaxia [...] Expulsadas las mujeres es raro ver hoy accidentes agudos de estas enfermedades, en cambio el número de obreros con Wassermann o Kahn positivos, pasa de 50 entre 900 obreros, y están

${ }^{78}$ Véase MOP, Memoria, 1937, p. 242. 
recibiendo tratamiento continuo perfectamente vigilado y bajo control. ${ }^{79}$

Vigilancia y control para un "triple beneficio": la salud del obrero, el aumento en su rendimiento y la disminución del gasto por el consumo de drogas específicas "demasiado costosas entre nosotros" ${ }^{80} \mathrm{El}$ director del dispensario médico del MOP en Caracas da cuenta del entusiasmo de aquellos años al referirse a los alcances del SMOP en estos términos:

La labor social y educativa al- [sic] en proyecto será enorme, contribuyendo con ella a la salud del individuo mismo como a la de su prole y familiares, pues el obrero adquiere de esa manera un concepto distinto de las enfermedades, se familiariza con el médico y él mismo se constituye a la postre en maestro de los que lo rodean enseñándoles en su ejemplo las ventajas que trae la llamada profilaxia social. ${ }^{81}$

\section{Leer y escribir}

A finales de enero de 1936, el ministro Pacanins se dirigió a su colega de Instrucción Pública con el fin de que designase un "pedagogo idóneo" para la organización de unas escuelas para obreros adscritas al nuevo Servicio de Educación Obrera (SEO), que acababa de ser creado a fin de "suministrar instrucción a los trabajadores de la obras públicas nacionales". La selección no pudo ser más acertada: Miguel

\footnotetext{
${ }^{79}$ Ibid., p. 320

${ }^{80}$ Ibid., p. 243.

${ }^{81}$ Ibid., p. 175.
}

Suniaga era miembro de la Sociedad Venezolana de Maestros de Instrucción Primaria, funcionario del Ministerio de Instrucción Pública y estaba elaborando en esos momentos, junto con el senador Luis Beltrán Prieto Figueroa y otros educadores, el controvertido proyecto de Ley Orgánica de Educación que éste presentaría, en abril de 1936, ante un congreso gomecista que lo descartó sin siquiera discutirlo. ${ }^{82} \mathrm{El}$ profesor Suniaga, que firmó también como fundador la segunda etapa del Movimiento de Organización Venezolana (ORVE), tuvo tiempo de poner en marcha en todo el territorio nacional las escuelas para obreros antes de fallecer, en diciembre de 1936, en un accidente de carretera cuando las recorría en visita de inspección. ${ }^{83}$

Durante esos meses, el servicio, apoyado en un modelo que reservaba para el Estado las competencias en materia de educación, afirmó la función social de la escuela. Las primeras estadísticas habían arrojado un resultado alarmante: del personal contratado en todo el país por el MOP, más de $90 \%$ de los tra-

${ }^{82}$ La Ley de Educación Nacional tuvo que esperar hasta 1940, luego de haberse presentado varios proyectos y de sortear innumerables escollos. El debate entre el Estado-docente y la escuela laica, fue el centro de la discusión desde que, en abril de 1936, el senador Luis Bel. trán Prieto Figueroa presentó su Proyecto de Ley Orgánica de Educación Nacional. Rómulo Gallegos también presentó un proyecto como ministro de Educación Nacional, pero finalmente fue aprobado el que presentó Arturo Uslar Pietri, ministro de Educación Nacional, en 1940. Véase Fernández Heres, Educación, 1997, y Pensamiento, núm. 22, pp. 191-212.

${ }^{83}$ Véase Magallanes, Partidos, 1977, p. 259, y MOP, Memoria, 1937, p. XXI. 
bajadores era analfabeto; "para el 31 de diciembre de 1936 aquella inquietante cifra bajaba a 33\%". ${ }^{84}$ Estos datos dieron el impulso necesario para definir un "Programa de Educación Obrera" adaptado a las circunstancias, y centrado especialmente en la desanalfabetización. El programa fue diseñado por la Oficina de Instrucción Primaria y Cívica del seo y, en febrero de 1936, era remitido para su aprobación al Ministerio de Instrucción Pública (MIP). En la correspondencia interministerial se explica que

se ha dado a la clase de instrucción cívica una mayor amplitud, teniendo muy presente los deseos del ciudadano presidente de la república, quien aspira a que todos los venezolanos, sin distinción de clases, y siempre dentro de las justas normas democráticas, adquieran una noción precisa del verdadero concepto de sus derechos y deberes, y se aparten de toda idea malsana incompatible con los principios que deben seguir en el orden de nuestra democracia. ${ }^{85}$

Las ideas malsanas como alteradoras del orden son lo suficientemente elocuentes como para que se insista en los objetivos que alientan la iniciativa. El programa se aprobó con algunas modificaciones -se agregaron unas nociones prácticas de geografía e historia patria-, de modo que, en abril de 1936 , un decreto presidencial creaba "100 servicios de enseñanza nocturna para obreros" en todo el país, de los cuales 20 se localizaron en el Distrito

\footnotetext{
* Véase MOP, Memoria, 1937, p. XXI.

" Véase Ministerio de Educación Nacional (en adelante MEN), Memoria, 1937, pp. 201-202.
}

Federal. El programa de enseñanza, que debía servir de pauta a la "desanalfabetización de los obreros", estaba com. puesto de las siguientes asignaturas: Lenguaje, Nociones de aritmética y Principios de moral y cívica.

Con el fin de seleccionar en cada obra, en cada campamento, el lugar adecuado para la instalación de las escuelas, el MOP nombró un comisionado técnico encargado de determinar "los sitios donde habría de construirse el tinglado o carpa que serviría de local a las escuelas". Cada una de ellas fue dotada de suficientes ejemplares del Libro inicial de lectura y escritura, preparado especialmente por el profesor Alejandro Fuenmayor -20000 ejemplares la primera edición-, además de cuadernos, lápices y pizarras. Por cada 50 obreros se enviaba a la escuela un pizarrón, una caja de tizas y una lámpara de carburo. El suministro de útiles y de material de enseñanza era gratuito, y tenía estampadas, como propaganda, las iniciales del MOP. La asistencia era controlada con una marca troquelada en la cédula de identificación del MOP, adicional a la de control del trabajo entregada por el ministerio. El maestro era el encargado de marcar la asistencia de acuerdo con una instrucción que señalaba: "todos los trabajadores hábiles para la instrucción deben concurrir a las escuelas". 86

\section{A la fuerza}

Mientras en el proyecto de Ley de Educación presentado por Prieto Figueroa

$$
{ }^{* 6} \text { Véase AGN-MAC, 1936, folios 56-58. }
$$


se fijaba que: "la instrucción de los obreros se hará a las horas más convenientes para el debido aprendizaje y en condiciones que no impliquen un motivo de fatiga más", en la práctica el Servicio de Educación Obrera no ofrecía mucho margen de libertad. Así, el periodista Enrique Bernardo Núñez escribió en el artículo ya citado:

un analfabeta puede ser tan feliz como un sabio que nada desea, aun cuando la vanidad se le asome por los agujeros de la capa. El todo está en tener cosecha y mujer e hijos sanos. $\mathrm{Y}$ al contrario, un hombre cultísimo puede ser un desventurado. A principio del año ocurrió un suceso joco-serio digno de consideración: un obrero agredió brutalmente al jefe de la sección de obras donde trabajaba porque éste quería obligarlo a ir a la escuela una vez concluida la recia labor. Suceso significativo. Pues si la intención del jefe era una intención loable, aquel hombre defendió su derecho $a$ ir donde quisiese -a dormir o a divertirse- después de su duro trabajo. ¿Cómo iba a ir a la escuela después de una jornada con pico, o encaramado a un andamio, a pleno sol? ${ }^{\text {87 }}$

Aunque menos dramáticos, los informes de las escuelas obreras en todo el país dan cuenta de los problemas: obreros que han sido retirados de las obras y se niegan a asistir alegando que necesitan esas horas para buscar trabajo; obreros que solicitan permiso para sustituir la asistencia a la escuela de su obra por la Escuela de la Asociación de Albañiles y no asisten a ninguna de las dos; rebeldía ante los descuentos del salario por las inasisten-

${ }^{87}$ Véase Núñez, Primer, 1936, pp. 371-372. cias; necesidad de dotar de alumbrado al local de la escuela -"a las cinco de la tarde, cuando hay neblina espesa, no se puede dar clase debido a la oscuridad"-; dificultad para dar clase porque los obreros son movilizados con frecuencia. ${ }^{88}$

Las estadísticas muestran que, en diciembre de 1936, más de 5000 obreros acudían a clases, de los cuales 2472 estaban inscritos en Caracas, con una asistencia promedio de $82 \%$. El ministro Pacanins no ocultaría su entusiasmo en la Memoria del año 1937, cuando decía:

de las obras públicas nacionales han salido en medio año trabajadores que, gracias a la acción benefactora de la instrucción, lograron cambiar de posición en el escenario social. De la humilde condición de hombres entredichos por la ignorancia, gracias a un empuje renovador bien interpretado, surgieron elementos capacitados para actuar en medios más altos, y así se ha dado ya el caso de que un simple obrero manual, gracias a su entusiasmo y contracción al estudio, haya sido designado maestro de sus propios compañeros. ${ }^{89}$

Sin embargo, cuando las nuevas escuelas de artes y oficios, dependientes del Ministerio de Educación, comenzaron a funcionar en cada capital de estado, y el Ministerio de Sanidad y Asistencia Social dio inicio al programa de construcción de edificaciones sanitarias previsto en el Plan Trienal, los programas internos de educación y salud del Ministerio de Obras Públicas decli-

88 Véase MOP, Memoria, 1937, pp. 105-131.

"sid., 1937, p. XXI. 


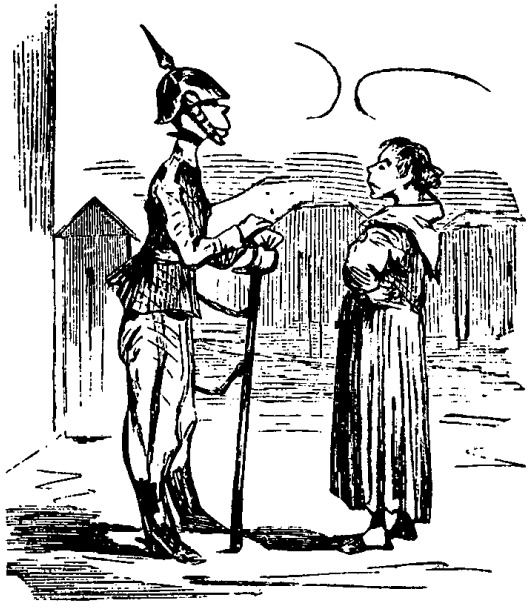

naron, aunque siguió siendo el gran constructor. La emergencia había redimido.

\section{MISIÓN CUMPLIDA}

El 7 de mayo de 1938, el presidente López Contreras presentó ante el Congreso el Plan Trienal. Para ese momento, la transición posgomecista, y en especial la excepcional coyuntura de 1936, habían cristalizado en un marco jurídico-administrativo completo. A diferencia del Programa de Febrero, con escuetas directrices para enfrentar la emergencia y argumentar la vocación y las intenciones generales -programa de corto plazo, de shock en términos actuales-, el Plan Trienal recogía y marcaba las competencias de cada uno de los entes administrativos creados, a los distintos niveles del sector público, para sentar "las bases de la proyección futura de esta obra de patria renovada y grande"..$^{90}$ Pero en el Plan Trienal la "trilogía inseparable: sanear, educar y poblar" tenía también en las obras públicas su apoyo fundamental. Tomás Pacanins había logrado la "proyección sobre el futuro" que esbozó en su intervención ante el gabinete en julio de 1936, en el sentido de "planificar de manera más acabada y terminante las obras por realizar, especificándolas en un programa y acompañando a cada proyecto el presupuesto correspondiente". Se anunciaba un plan, apartado "del nocivo hábito de complacencias inconsultas para con los intereses regionales o privados", que procuraba evitar la construcción de obras aisladas no articuladas al conjunto. Plan, programa y presupuesto apoyados en los datos, estadísticas y cálculos elaborados por el MOP a partir de la información enviada por cada uno de los despachos del gabinete, los viejos y los recién creados. En el Plan Trienal, el ministro Pacanins logró incorporar hasta sus planteamientos de julio de 1936 sobre las modalidades de financiamiento de las obras al separarlas entre aquellas que se ejecutarían con recursos ordinarios y aquellas que, por su "importancia decisiva" y su costo "demasiado crecido", requerían de "recursos cuantiosos, tan grandes que se apartan de las posibilidades que señalan las entradas regulares del fisco". ${ }^{91}$ Así, los

\footnotetext{
${ }^{90}$ Véase Suárez Figueroa, Programas, 1977, p. 197.

${ }^{91}$ Véase AGN-MAC, 1936, pp. 49-52, y Suárez Figueroa, Programas, 1977, t. 1, pp. 197-232.
} 
364000000 del Plan Trienal aparecen repartidos en 160 con cargo a los recursos ordinarios y 204 bajo un plan de financiamiento a largo plazo. Sin embargo, luego de que López Contreras pidiese, en julio de 1938, la renuncia a su gabinete, el 1 de agosto Tomás Pacanins dejó de ser ministro de Obras Públicas. Varias son las hipótesis plausibles para explicar por qué el mentor fundamental del Plan Trienal no fue encargado de ejecutarlo. La incursión del MOP en terrenos ajenos a su propia naturaleza, y su reticencia a abandonar las competencias adquiridas en los tiempos de crisis, a pesar de que los nuevos ministerios iban asentando sus programas de acción, podría ser una explicación. También el modelo de país que impulsaba el proyecto político de Tomás Pacanins -el Partido Nacionalistay la necesidad que tuvo de impulsarlo desde fuera de la administración pública.

Sin embargo, es posible sumar a am bas hipótesis una adicional, construida desde un horizonte de actuación del ministro no tratada aquí, pero desarrollada en otros textos: la injerencia del gobierno nacional sobre el municipal en el caso del plan de urbanismo para la capital. ${ }^{92}$ Se resumiría de este modo. En febrero de 1936, Elbano Mibelli es designado gobernador del Distrito Federal en sustitución de Félix Galavís. Muy rápidamente trasciende a la prensa que un ciudadano francés, representante de una empresa constructora de obras públicas, y un urbani-

92 Véase Martín Frechilla, Planes, 1994, pp. 345-362, y "Urbanismo", 1993, pp. 383-394.

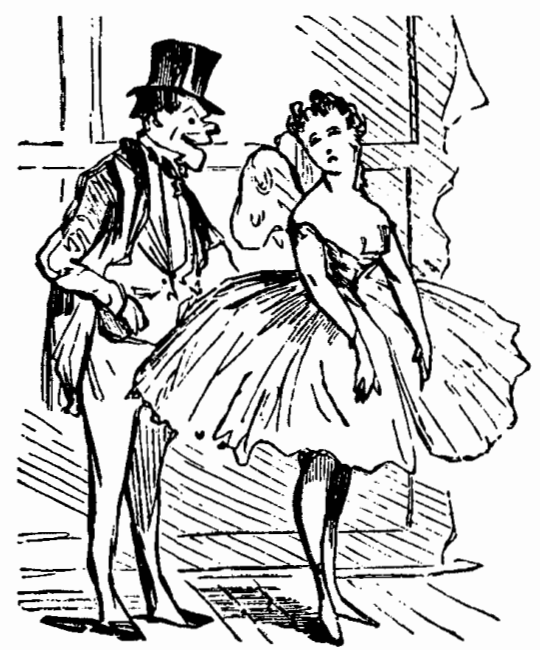

zador venezolano de origen francés, están gestionando con la Gobernación la contratación de unos técnicos urbanistas franceses para la elaboración de un plan de urbanismo para la capital. El urbanizador francovenezolano propone la construcción de una gran avenida como eje del desarrollo urbano. La noticia se filtra a la prensa, ventilada por un escritor de prestigio, que se encarga de arremeter contra el contrato sin licitación y contra los riesgos financieros de la operación. Mientras, la Asociación Venezolana de Ingenieros (AVI), que agrupa a los ingenieros cuyos títulos no son revalidables y de la cual es miembro Tomás Pacanins, protesta porque existen en el país profesionales capaces de realizar el plan de urbanismo. Para demostrarlo, la AVI y el MOP elaboran, entre octubre y diciembre de 1936, un plan de urbanis- 
mo para el valle de Caracas. En julio de 1937 la oposición toma posesión del Concejo Municipal de Caracas luego de haber ganado abrumadoramente las elecciones. ${ }^{93}$ Mientras el gobernador Mibelli intenta tramitar la contratación de los franceses, la oposición, mayoritaria en el Concejo, solicita que el MOP presente su plan ante la Cámara. En noviembre de 1937, el Concejo Municipal aprueba el Plan de Urbanismo para el Valle de Caracas elaborado por el MOP y la AVI. El gobernador solicita ante la Corte Federal y de Casación la nulidad del acto por lesivo a la propiedad privada del suelo. A finales de diciembre de 1937, la Corte le da la razón al gobernador. Sin embargo, el Concejo, lisego de un nuevo informe jurídico, lo aprueba en marzo de 1938. Le esperaba una gaveta, porque a comienzos de mayo de 1938 el gobernador Mibelli, haciendo caso omiso de la decisión del Concejo Municipal, había firmado un contrato con la oficina del urbanista Henri Prost -a la cual se incorporaron para este proyecto Jacques Lambert y Maurice Rotival. Ellos dos serían los encargados en Caracas de elaborar el Plan Monumental de Caracas de $1939 .{ }^{94}$

${ }^{93}$ En el sistema electoral sancionado por la Constitución de 1936, los Concejos Municipales elegían de su seno a los representantes a la Cámara de Diputados, así como las Asambleas Legislativas de los estados lo hacían para la Cámara del Senado, de ahí la importancia de estas elecciones para ir renovando progresivamente el Congreso gomecista. De acuerdo con la Constitución de 1936, el Congreso era el encargado de elegir al presidente de la república.

${ }_{94}$ De acuerdo con la Ley Orgánica del Distrito Federal, sancionada el 28 de julio de 1937,
Tomás Pacanins dejó de ser ministro de Obras Públicas el primero de agosto de 1938. Los componentes perfilados de su actuación permiten, además de valorarla, situar un escenario de privilegio para hacer lo propio con la transición posgomecista que, ya estabilizada, iniciaba una nueva etapa. La historia que siguió al análisis de coyuntura propuesto escapa a este texto, sin embargo, es posible señalar unas claves. Ante el avance de las ideas de los partidos, digamos de izquierda o de más profunda raíz social, avance reflejado en los éxitos en las elecciones municipales, el presidente López Contreras fundó un partido de gobierno, la Agrupación Cívica Bolivariana (ABC), estructurada a partir de los cuadros de los distintos niveles de la administración pública y con el Programa de Febrero enunciado como programa político. ${ }^{95}$ De esta forma el militar resolvió la participación como civil en la vida política. Al terminar su mandato en 1941 , la agrupación creada por el general López Contreras languideció. El Congreso Nacional, todavía de mayoría gome-

la autoridad municipal la componían el gobernador designado por el presidente de la república, y el Concejo Municipal elegido por votación. El gobernador del Distrito Federal, en este caso Elbano Mibelli, era miembro con voz y con voto en los asuntos de su entidad del gabinete ejecutivo. Pacanins y Mibelli se sentaban desde julio de 1937 en la misma sala de reuniones.

${ }^{95}$ Véase Magallanes, Partidos, 1977, pp. 317-324. Con respecto a la concepción del partido lopecista dice este autor, de tendencia socialdemócrata, lo siguiente: "tuvo como base ideológica la doctrina política bolivariana, adoptada caprichosamente en el sentido de fuerza espiritual y patriótica", p. 317. 
cista, eligió como nuevo presidente al ministro de Guerra y Marina, general Isaías Medina Angarita. La transición política discurrió con él por caminos políticamente más tolerantes, y su programa de gobierno se afirmó en políticas de desarrollo nacional impulsadas por el Estado en la difícil coyuntura de la segunda guerra mundial. Pero las cuentas militares y civiles no saldadas socialmente con el pasado gomecista se agruparon en octubre de 1945 en un exitoso golpe de Estado, para el cual los jóvenes militares de la Unión Militar Patriótica buscaron apoyo en los líderes civiles del partido Acción Democrática, encabezados por Rómulo Betancourt.

Pero el dispositivo de obras públicas puesto en funcionamiento entre 1936 y 1938 se mantuvo. El presupuesto del MOP creció de $20 \%$ del total del presupuesto nacional, a $26 \%$ durante el Trienio Socialdemócrata (1945-1948), hasta alcanzar casi $40 \%$ durante la década 1948-1958 bajo el gobierno del general Pérez Jiménez. Cuando en 1976 se liquidó el MOP, dividiéndose sus atribuciones en dos nuevos ministerios, este porcentaje era menor a $10 \%$. El poder político y clientelar que había llegado a acumular todos esos años se había derrumbado, para renacer en otras instancias de la administración pública.

\section{ARCHIVOS}

AGN Archivo General de la Nación, Ministerio de Agricultura y Cría, Varios, carpeta 82 , legajo 248 , expediente 894, 1936.

\section{HEMEROGRAFÍA}

-Abora.

-La Esfera.

\section{PubliCACIONES OfiCIALES}

\section{Gaceta Oficial}

-"Decreto por el cual se crea la Oficina Nacional del Trabajo", núm. 18.893, 1936, pp. 106.950-106.951.

."Ley del Trabajo", núm. extraordinario, 1936, pp. 1-24.

-Mensajes presidenciales, Presidencia de la República, Caracas, 1970, tomo I (1830-1875); 1971, tomo II (1876-1890); tomo III (1891-1909); tomo IV (1910-1939).

-Castro, Cipriano, "Mensaje del general Cipriano Castro, presidente de la República, al Congreso de 1904", tomo III, pp. 359-369.

-Crespo, Joaquín, "Mensaje del general Joaquín Crespo, presidente de la República, al Congreso Nacional de 1886", tomo II, pp. 259-300.

-López Contreras, E., "Mensaje que el general E. López Contreras, presidente de los Estados Unidos de Venezuela, presenta al Congreso Nacional en 1936", tomo Iv, pp. 281 286.

_Mensaje que el general E. López Contreras, presidente de los Estados Unidos de Venezuela, presenta al Congreso Nacional de 1937", tomo N, pp. 287-307.

-Gómez, J. V., "Mensaje que el general J. V. Gómez, presidente de los Estados Unidos de Venezuela, presenta al Congreso Nacional en 1934", tomo IV, pp. 259-267.

-Monagas, José Tadeo, "Mensaje que dirige el presidente de la República, general José Tadeo Monagas, al Congreso de la Nación en 1856", tomo I, pp. 219-229. 
Tovar, Manuel Felipe de, "Mensaje del doctor Manuel Felipe de Tovar, vicepresidente de la República, encargado del poder ejecutivo, al Congreso de 1860", tomo I, pp. 265-272.

-Ministerio de Educación Nacional, $M e$ moria, MEN, Caracas, 1937.

-Ministerio de Fomento, Memoria, MF, Caracas, 1937.

-Ministerio de Obras Públicas, Memoria, MOP, Caracas, años: 1902, 1937,1940.

-Ministerio del Trabajo y de Comunicaciones, Memoria, MTC, Caracas, 1937.

-Ordenanzas, resoluciones $y$ acuerdos de la $H$. D. Provincial de Caracas aprobados en 1851, Imprenta de Ramón Alcalde Piña, Caracas, 1851.

-Recopilación de leyes y decretos de Venezuela, Imprenta Nacional, Caracas.

-"Ley de Sanidad de 3 de julio de 1912", tomo Xxxv, 1912, pp. 407-408.

-"Ley de Talleres y Establecimientos Públicos de 26 de junio de 1917", tomo XI, 1917, pp. 165-166.

-"Ley del Trabajo de 28 de julio de 1928", tomo LI, 1929, pp. 430-436.

"Decreto de 12 de marzo de 1937, por el cual se adscriben al Ministerio de Comunicaciones la Oficina Nacional del Trabajo, las Inspectorías del Trabajo y Comisiones Especiales del Trabajo y se dispone que dicho departamento se denomine Ministerio del Trabajo y de Comunicaciones", tomo LX, 1938, p. 184.

\section{COLECCIONES, COMPILACIONES DOCUMENTALES}

-Pensamiento conservador del siglo XIX, Monte Ávila Editores, Caracas, 1991.

-Pensamiento liberal del siglo XIX, Monte Ávila Editores, Caracas, 1991.

-Pensamiento politico venezolano del siglo XIX. Textos para su estudio, Congreso de la República, Caracas, 1983.
-Pensamiento político venezolano del siglo XX. Documentos para su estudio, Congreso Nacional, Caracas, 1983, 1986.

-Actas y conclusiones del Primer Congreso de Municipalidades de Venezuela, 1913, tomo IV, núm. 9.

-El debate político en 1936 , tomo vi, vol. 1, núm. 14.

-Mensajes y Memorias, 1935-1941, tomo vi, vol. 1 , núm. 17.

-Decretos y Memorias del ejecutivo nacional (1935-1941), tomo viII, vol. 1 , núm. 18.

-El debate parlamentario (19361941), tomo vil, vol. vi, núm. 22.

-Los partidos políticos (1936-1941), tomo vili, vol. XVI, núms. 31 y 32 .

\section{BIBLIOGRAFÍA}

-Adriani, Alberto, "Nota", Revista de Hacienda, núm. 1, 1936, pp. 7.8.

-Arcila Farias, Eduardo, Centenario del Ministerio de Obras Públicas. Influencia de este Ministerio en el desarrollo (18741974), MOP, Caracas, 1974.

-Archila, Ricardo, Historia de la Sanidad en Venezuela, Imprenta Nacional, Caracas, 1956, 2 tomos.

-Barret-Ducrocq, Françoise, "La mobilisation philanthropique à Londres dans la période victorienne: una sainte violence" en Bec, Pbilantropies, 1994, pp. 17-28.

-Battaglini, Óscar, Legitimación del poder y lucha politica en Venezuela, 19361941, Consejo de Desarrollo Científico y Humanístico-Universidad Central de Venezuela, Caracas, 1993.

-Bec, Colette y otros (comps.), Pbilantropies et politiques sociales en Europe (Xvile-XXe siècles), Anthropos, París, 1994.

-Boggiano, Guillermo y Rafael Mújica, Seguridad social, Edisa, Caracas, 1972.

-Caldera, Rafael, Derecbo del trabajo, Tipografia La Nación, Caracas, 1939. 
-Camacho, Óscar Olinto, "Venezuela's national colonization programme: the Tovar colony, a german agricultural settlement", Journal of Historical Geography, vol. 10, núm. 3, 1984, pp. 279-289.

-Chiossone, Tulio, El decenio democrático inconcluso, 1935-1945, Editorial Exlibris, Caracas, 1989.

-Cilento, Alfredo y otros, "El dispositivo de obras públicas en Venezuela (18741976)" en Martín Frechilla y Texera Arnal, Modelos, 1999.

-Diccionario de Historia de Venezuela, Fundación Polar, Caracas, 1997, 4 tomos.

-Diez, Julio, Estudios de Derecho Social, Tipografia Americana, Caracas, 1940.

-Duprat, Catherine, "Des Lumières au premier XIXe siècle: voie française de la philanthropie" en Bec y otros, Pbilantropies, 1994, pp. 3-15.

-Egaña, Manuel, Reflexiones acerca del medio físico venezolano y sus reacciones frente al dominio del bombre, Ediciones de la Academia Nacional de Ciencias Económicas, Caracas, 1988.

-Fernández Heres, Rafael, La educación venezolana bajo el signo del positivismo, Academia Nacional de la Historia. Caracas, 1994. bajo el signo de la escuela nueva (19361948), Academia Nacional de la Historia, Caracas, 1997.

-Fuenmayor, Juan Bautista, Historia de la Venezuela politica contemporánea, 1899-1969, edición del autor, Caracas, 1976 , tomo II.

-García Ponce, Antonio, Los pobres de Caracas 1873-1907. Un estudio de la pobreza urbana, Instituto Municipal de Publicaciones, Caracas, 1995.

- Grases, Pedro y Manuel Pérez Vila (comps.), Testimonios sobre la formación para el trabajo (1539-1970), INCE, Caracas, 1972.

-Gutiérrez Alfaro, Tito, Documentos inéditos para la bistoria del seguro social obligatorio en Venezuela, s. e., Caracas, 1966.

-Hermoso, Juan Manuel, 1936: programas vs poder, Consejo de Desarrollo Científico y Humanístico-Universidad de $\mathrm{Ca}$ rabobo, Valencia, 1991.

-Kott, Sandrine, "Solutions libérales ou étatiques à la question sociale en Allemagne au XIXe siècle" en Bec y otros, Pbilantropies, 1994, pp. 177-185.

-López Contreras, Eleazar, Páginas para la bistoria militar de Venezuela, Tipografía Americana, Caracas, 1944.

-, Proceso politico social, 19281936, Editorial Áncora, Caracas, 1955. , Gobierno y administra. ción, 1936-1941, Editorial Arte, Caracas, 1966.

- Magallanes, Manuel Vicente, Los partidos políticos en la evolución histórica venezolana, Monte Ávila Editores, Caracas, 1977.

-Martín Frechilla, Juan José, "El urbanismo francés en Venezuela de 1936 a 1950", Estudios Demográficos y Urbanos 23, vol. 8, núm. 2, 1993, pp. 377-413.

, Planos, planes y proyectos para Venezuela, 1908-1958 (Apuntes para una bistoria de la construcción del pais), Fondo Editorial Acta Científica Venezolana/ Consejo de Desarrollo Científico y Huma. nístico-Universidad Central de Venczuela, Caracas, 1994.

y Yolanda Texera Arnal (comps.), Modelos para desarmar. Instituciones $y$ disciplinas para una bistoria de la ciencia y la técnica en Venezuela, Consejo de Desarrollo Científico y Humanístico-Universidad Central de Venezuela, Caracas, 1999.

-Moleiro, Rodolfo, De la dictadura a la democracia. Eleazar López Contreras, lindero y puente entre dos épocas, Editorial Pomaire, 3a. ed., Caracas, 1993.

-Mora Contreras, Óscar, Seguridad so. cial $y / o$ bienestar social o fortaleza estatal, Editorial Lisbona, Caracas, 1978. 
-Núñez Enrique Bernardo, "El primer semestre", Pensamiento, tomo vil, vol. XII, núm. 28, 1983, pp. 371-372.

-Pacanins, Feliciano, 51 años al servicio de Venezuela, Empresa El Cojo, Caracas, 1970.

-Parra, Dario, Accidentes del trabajo, Tipografía Criollo, Caracas, 1942, 2 tomos.

-Parra Aranguren, Fernando Ignacio, Antecedentes del Derecbo del Trabajo en Venezuela. 1830-1930, Universidad del Zulia, Maracaibo, 1965.

-Penzini Hernández, Juan, Democracia habemos...!, Cooperativa Artes Gráficas, Caracas, 1939.

-Polanco Alcántara, Tomás, Con la pluma y con el frac, Editorial Arte, Caracas, 1982.

torial Arte, Caracas, 1985.

-Razetti, Luis, Obras completas. II Divulgación, Ministerio de Sanidad y Asistencia Social, Caracas, 1962.

-Skocpol, Theda, Los origenes de la política social en los Estados Unidos, Centro de Publicaciones-Ministerio del Trabajo y Asuntos Sociales, Madrid, 1996.

-Suárez Figueroa, Naudy (comp.), Programas politicos venezolanos de la primera mitad del siglo $\mathrm{XX}$, Colegio Universitario Francisco de Miranda, Caracas, 1977, tomo 1 .
-Tanghe, Fernand, Le droit au travail entre bistoire et utopie, Facultès Universitaires Saint-Louis/Institut Universitaire Européen, Bruselas/Florencia, 1989.

-Topalov, Christian, "Invention du chômage et politiques sociales au début du siècle", Les Temps Modernes, núms. 496/ 497, 1987, pp. 53-92.

-Topalov, Christian, "L'enquête de Charles Booth et le peuple de Londres, 18861891", Genèses, núm. 5, 1991, pp. 5-34.

-Vilchez, Rodolfo (comp.), Compilación constitucional de Venezuela, Servicio Autónomo de Información Legislativa-Congreso de la República, Caracas, 1996.

-Villegas, Silvio, La politica exterior de Juan Vicente Gómez, Universidad de Los Andes, Caracas, 1993.

-Vivas, Freddy, Venezuela en la Sociedad de las Naciones 1920-1939: descripción y análisis de una actuación diplomática, Universidad Central de Venezuela, Caracas, 1981.

-Zumeta, César, "(La defensa económica de Venezuela). Exposición que somete al general J. V. Gómez, comandante en jefe del Ejército y presidente electo de Venezuela, Nueva York, 19 de octubre de 1918", Boletin del Archivo Histórico de Miraflores, núms. 17/18, 1962, pp. 281-292.

-Zúñiga Cisneros, Miguel, Ensayos, Ediciones FACES-UCV, Caracas, 1973. 